ESTIMATING POWER CONSUMPTION IN CITY OF TORONTO: A CASE STUDY

\author{
Syed Muhammad Shees Saeed \\ B.S. in Biomedical Engineering \\ Sir Syed University of Engineering and Technology \\ Karachi, Pakistan, 2010
}
A project presented to Ryerson University
in partial fulfillment of the
requirements for the degree of
Master of Engineering
in the Program of

Electrical and Computer Engineering

Toronto, Ontario, Canada, 2016

C(Shees Saeed) 2016 


\section{AUTHOR'S DECLARATION}

\section{AUTHOR'S DECLARATION FOR ELECTRONIC SUBMISSION OF PROJECT}

I hereby declare that I am the sole author of this project. This is a true copy of the project including any required final revisions, as accepted by my examiners.

I authorize Ryerson University to lend this project to other institutions or individuals for the purpose of scholarly research.

I further authorize Ryerson University to reproduce this project by photocopying or by other means, in total or in part, at the request of other institutions or individuals for the purpose of scholarly research.

I understand that my project may be made electronically available to the public. 


\title{
Estimating Power Consumption in City of Toronto: A Case Study
}

\author{
2016 \\ Syed Muhammad Shees Saeed \\ Electrical and Computer Engineering \\ Ryerson University
}

\begin{abstract}
Ontario's energy system provides reliable and clean energy to the province. The demand of electricity is rising throughout the world, thus Ontario's goal is to maintain the demand and generation of electricity. In this report we have discussed the electricity demand of Ontario and divided the sectors into categorical data of electricity and studied peak hour demands of Toronto. First, we have briefly discussed the introduction, which includes the history, geographical location and socio-economic importance of Toronto. Then in the literature review we have highlighted Ontario's generation of electricity, which is produced by various renewable energy sources and have further discussed their drawbacks. The survey is focused on the demand of electricity in Toronto by calculating the requirement and then distributing the data into 24 hours, from which we have studied peak hours demand in various categories such as residential buildings, offices, shops etc. The purpose of this survey is to monitor the electricity demand in order to reduce power outages and blackouts due to technical issues.
\end{abstract}




\section{Acknowledgment}

I am grateful to acknowledge my supervisor Dr. K. Raaheimfar, from the Electrical and Computer Engineering Department at Ryerson University.

I have had the great pleasure of having Dr. K. Raaheimfar as my supervisor. I found his instructions and knowledge both insightful, yet challenging. He has always been present to support my project. With his efforts, I was able to complete my project. 


\section{Table of Contents}

Author's Declaration $\quad$ ii

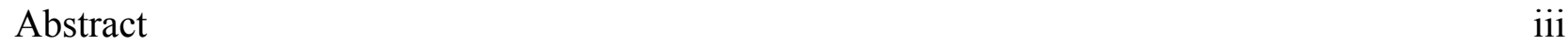

Acknowledgment iv

List of Tables $\quad$ viii

List of Figures

1. Introduction 1

1.1 Capital of Ontario 2

1.2 Geographical location of Toronto 3

1.3 Major Attraction of Toronto 3

2. Literature Survey $\quad 5$

2.1 Electricity’s Generation in Ontario

$\begin{array}{lr}2.2 \text { Types of renewable sources } & 6\end{array}$

2.3 Ontario Long Term Energy Plan $\quad 8$

2.4 Defining Generation Sources $\quad 9$

$\begin{array}{ll}2.4 .1 \text { Wind Energy } & 10\end{array}$

2.4.2 Solar Energy 11

2.4.2.1 Photovoltaic: Electricity from the Sun 12

2.4.3 Hydro Power 12

2.4.4 Geothermal Power 13

$\begin{array}{ll}2.4 .5 \text { Bio Energy } & 14\end{array}$

$\begin{array}{ll}\text { 2.4.6 Bio Gas } & 14\end{array}$

$\begin{array}{ll}\text { 2.4.7 Bio mass } & 15\end{array}$

$\begin{array}{ll}2.4 .8 \text { Nuclear Power } & 15\end{array}$

2.5 Barriers to Renewable Energy Technologies 16

2.5.1 Commercialization Barriers 17

$\begin{array}{ll}2.5 .2 \text { Infrastructure } & 17\end{array}$

$\begin{array}{ll}\text { 2.5.3 Economics of Scale } & 17\end{array}$ 
2.5.4 Unequal government subsidies and taxes

2.5.7 Institutional Barriers

$\begin{array}{ll}2.8 \text { Distributed Generation in Toronto } & 21\end{array}$

2.8.1 Distribution Planning \& Transformation $\quad 21$

$\begin{array}{ll}\text { 2.8.2 The DESN Station } & 22\end{array}$

$\begin{array}{ll}\text { 2.8.3 The Distribution Network } & 23\end{array}$

$\begin{array}{ll}2.9 \text { Consumption in Toronto } & 24\end{array}$

2.10 Typical Electricity requirement in Toronto 25

$\begin{array}{ll}2.11 \text { Benefits of Distributed Generation in Toronto } & 27\end{array}$

$\begin{array}{ll}2.11 .1 \text { System Benefit } & 27\end{array}$

$\begin{array}{ll}2.11 .1 .1 \text { Reduce peak demand } & 27\end{array}$

2.11.1.2 Potential for DHG to reduce peak load 27

2.11.1.3 Reduce line loses, Increase system efficiency 28

$\begin{array}{ll}\text { 2.11.2 Environmental Benefits } & 28\end{array}$

2.11.2.1 Reduce carbon footprint, lower GHC emission $\quad 28$

2.11.2.2 Increase the amount of clean energy 29

$\begin{array}{ll}\text { 2.11.2.3 Reduced fuel consumption } & 29\end{array}$

3. Methodology

4. Discussion

4.1 Town House Assessment 33

$\begin{array}{ll}4.2 \text { Transit System Assessment } & 36\end{array}$ 
$\begin{array}{ll}\text { 4.3 Government Building Assessment } & 37\end{array}$

4.4 Community Centers Assessment 39

4.5 Residential Buildings Assessment 40

$\begin{array}{ll}4.6 \text { Office Assessment } & 43\end{array}$

4.7 Hospital Assessment $\quad 44$

4.8 School Assessment 46

$\begin{array}{ll}4.9 \text { Library Assessment } & 48\end{array}$

4.10 Malls Assessment $\quad 49$

$\begin{array}{ll}4.11 \text { Industrial Assessment } & 50\end{array}$

$\begin{array}{ll}\text { 4.12 Shops Assessment } & 51\end{array}$

4.13 Miscellaneous Assessment 53

4.14 Combined Categorical Assessment

4.15 Emerging Technologies in Ontario

4.15.1 Smart Grid $\quad 55$

$\begin{array}{ll}\text { 4.15.2 Smart Meter } & 56\end{array}$

4.15.3 Smart Metering \& Energy Monitoring 57

4.16 Ontario's Green Button Initiative $\quad 58$

5. Conclusion $\quad 59$

$\begin{array}{lc}\text { References } & 61\end{array}$ 


\section{List of Tables}

Table 2.1: Renewable Energy Sources considered in the energy plan 9

Table 2.2: Generation and Consumption rate of Renewable Sources 24

Flow Chart 3: Categorical distribution of load distribution 32

\section{List of Figures}

Figure 2.1: Typical generation in Ontario (2012) 6

Figure 2.2: Typical Demand in Ontario-2012 20

Figure 2.3: The DESN Station $\quad 22$

Figure 2.4: Categorical distribution of electricity in Toronto 25

Figure 2.5: Categorical distribution of electricity in Toronto 26

Figure 4.1(a): Graphical representation of electricity requirement in Town Houses (Summer) 34

Figure 4.1(b): Graphical representation of electricity requirement in Town Houses (Winter) 35

Figure 4.2: Graphical representation of electricity requirement in Transit System 36

Figure 4.3: Graphical representation of electricity requirement in Government Building 38

Figure 4.4: Graphical representation of electricity requirement in Community Centre 39

Figure 4.5(a): Graphical representation of electricity requirement in Residential (Summer) 41

Figure 4.5(b): Graphical representation of electricity requirement in Residential (Winter) 42

Figure 4.6: Graphical representation of electricity requirement in Offices 44

Figure 4.7: Graphical representation of electricity requirement in Hospitals 45

Figure 4.8: Graphical representation of electricity requirement in Schools 47

Figure 4.9: Graphical representation of electricity requirement in Library 48

Figure 4.10: Graphical representation of electricity requirement in Malls 49

Figure 4.11: Graphical representation of electricity requirement in Industries 51

Figure 4.12: Graphical representation of electricity requirement in Shops 52

Figure 4.13: Graphical representation of electricity requirement in Miscellaneous 53

Figure 4.14: Graphical representation of all the categories $\quad 54$

Figure 4.15: A Smart Grid $\quad 56$ 


\section{Introduction}

Ontario's standard of living is highly dependent on energy, particularly electrical Energy. In fact it is true that the rich and poor in the world are discriminated on the basis of their access to reliable and affordable electricity. The future is even darker. It is likely that more discrimination will be observed among the rich and poor communities, not only on the basis of affordable and reliable energy, but also on environmental sustainable energy [1].

The electricity production model that has been extremely beneficial for Ontario and numerous other areas and communities, until now has been set to exploit the strong economies of centralized generation plants which is spread on a large scale and to deliver this energy to other consumers and customers spread over a vast network of high and low voltage transmission of electricity and distribution wires. This model results in vast cost benefits [1].

The rejection from both sides, i.e. large-scale generation plants in some areas and the extreme public opposition to the development and construction of interlocking distribution and transmission lines throughout the vast province is causing too much stress to economy. In the development of Ontario's electricity system, the involvement of First Nations is highly significant. The interests of these communities must be taken into account for any future development [1].

To create a higher standard of living in Toronto, the most demanding element required is the ease of access to affordable, sound, and stable sources of energy. The uses of energy are plentiful. It is used to heat and cool most surroundings like buildings, workplaces, and areas of leisure. Energy is essential to operate the industrial and commercial processes that spawn Toronto's revenue and wealth. We can move goods and people if we have energy, which also helps in bringing food into our city. It is energy that runs our infrastructure needs as our requirements including the supply of hygienic water. Everyday life is not complete without energy [2].

Energy challenges are however growing in Toronto. Some of the challenges faced by residents include the cost of energy rising tremendously, its growth for demand, change in 
weather affecting higher peak energy needs, fading infrastructures of energy and the expanding influence of our energy choices on the environment locally and globally [2].

Our quality of life at the moment is highly risky, considering the impacts of climate change in Toronto. Greater energy consumption in the summer season can cause energy outages, revolving power cuts, extreme heat waves affecting the poor, sick and aged people, and those very heavy storms and rains resulting in transmission failures, death and power failures. All these dangers and risks are real and too expensive for Toronto's infrastructure, local economy and health. These risks are a threat now but there is a possibility that these will grow throughout our lifetime until the next generation [2].

These demonstrate the need for better plans to generate, manage and use energy in Toronto. Currently, it is known to Toronto residents that they need to deal with energy differently than they did in the past. A number of businesses in Toronto and households are taking initiatives to incorporate features related to energy into their lives and operations, hence realizing economic savings from their actions. New and latest sources of energy are already being looked upon which provide more clean local power. The Sustainable Energy Plan of Toronto is a descriptive and detailed analysis of the way our city consumes energy. This will definitely be quite helpful for the city government and other stakeholders to plan for the future with a better strategy [2].

\subsection{Capital of Ontario - Toronto}

Out of the most rapidly growing cities worldwide, Toronto is one of the fastest-paced cities in North America. Toronto ranks $4^{\text {th }}$ in population size in North America as well as in Canada and is known to be the provincial capital of Ontario. Its population is approximately 2.8 million and is increasing rapidly. A number of sectors including Economic and Business development, Tourism and Entertainment, Centers of Arts and Cultures, Commercial and Industrial sectors are now a part of the leading economy of Toronto. It is also a big challenge to continuously maintain and develop the infrastructure of this enormous city [3]. 


\subsection{Geographical location of Toronto}

Toronto, one of the biggest cities in Canada, occupies a total area of around 630 $\mathrm{km}^{2}$ (243 sq. mi). Beautiful Lake Ontario is present at the south of Toronto. To the west there is Etobicoke Creek and Highway 427. In the north and in the east there are Steeles Avenue and the Rouge River respectively. The city of Toronto is further trisected by two small rivers along with their tributaries named the Humber River in the west end and the Don River east of downtown. Their direction of flow is southward to Lake Ontario at Humber Bay and Toronto Harbour respectively. These are also a part of Waterfront. The closest neighboring cities of Toronto are Mississauga and Brampton within the Regional Municipality of Peel, Markham and Vaughan in the Regional Municipality of York, and in the Regional Municipality of Durham there is Pickering. The GTA (Greater Toronto Area) comprises of the regional municipalities of Peel, Halton, Durham and York [4].

\subsection{Major Attraction of Toronto}

Numerous high-rise office buildings, including the twin-towered City Hall, cluster in the Downtown area. Rising far above them is the 1,815-foot (553-m) CN (Canadian National) Tower, one of the tallest freestanding structures in the world. Nearby are Ontario Place, a recreation and entertainment complex; Exhibition Place, site of the annual Canadian National Exhibition; the Hockey Hall of Fame [3].

The Sky-Dome stadium, site of sports events, concerts, conventions, and trade shows.

The Maple Leafs (professional hockey) and the Raptors (professional basketball) play at the Air Canada Center. The Blue Jays are Toronto's professional baseball team [3].

The Ontario Science Centre features scientific and technological exhibits that allow visitor participation. The Metro Toronto Zoo and Casa Loma, a 98-room mansion built in the style of a castle, attract many visitors. Among the city's many parks offering a variety of recreational facilities are Toronto Islands Park, in Lake Ontario, and High Park [3].

Cultural institutions like the Royal Ontario Museum, Art Gallery of Ontario is known for its modern sculptures. The Hummingbird Centre for the Performing Arts is the home of the Canadian Opera Company and the National Ballet of Canada. The Toronto Symphony performs 
in Roy Thomson Hall. The Toronto Centre for the Performing Arts and the Royal Alexandra Theatre are also in Toronto. Prominent among educational institutions in metropolitan Toronto are the University of Toronto, the largest university in Canada, York University, and the Ryerson Polytechnic University [3]. 


\section{Literature Survey}

\subsection{Electricity's Generation in Ontario}

According to IESO power data, As of March $23^{\text {rd }}, 2015$. Ontario is generating 34,367 MW of electricity [5].We have considered the data of IESO-Electricity Generation of Ontario (2012), and generation is 36,336 MW/Hr. Ontario has a strong energy system, which provides efficient and clean energy to the entire province; it has various sources from which we can obtain reliable energy. In this figure we explain the generation of electricity of Ontario, nuclear representing 12,998 $\mathrm{MW} / \mathrm{Hr}$ It is one of the biggest sources of energy and provides safe, reliable and affordable energy to the province. Nuclear power releases less toxic emissions and greenhouse gases compared to coal, and is environmental-friendly.

The generation of Natural Gas is $9987 \mathrm{MW} / \mathrm{Hr}$, which is basically a mixture of methane and other gases, which can be found in underground. The supply of natural gas comes from Alberta, Saskatchewan and British Columbia because there is less of Natural Gas present in Ontario. The generation of renewable energy is clearly understandable in the figure 2.1. As Solar generates $150 \mathrm{MW} / \mathrm{Hr}$., it is free and easily available because of the sunlight and endless supply of the daylight; it is one of the finest additions in the renewable energy sources. Hydroelectricity generates $7939 \mathrm{MW} / \mathrm{Hr}$. Through the flow of the water; it is also known as Water Power and is being a reliable source to fuel Ontario's growth for over 100 years. Wind Power generates 1725 MW/Hr.

It is increasing rapidly and gaining a reputation of completely sustainable and generating clean form of electricity thus having potential to fulfill the demand of energy in the province. Biogas generates $122 \mathrm{MW} / \mathrm{Hr}$. and Geothermal produces $122 \mathrm{MW} / \mathrm{Hr}$., whereas Coal generates $3293 \mathrm{MW} / \mathrm{Hr}$., it is not the cleanest source and generates emissions, so our province plans to reduce the coal fired plants in order to improve the environment and move towards renewable sources which is a much better option [6]. 


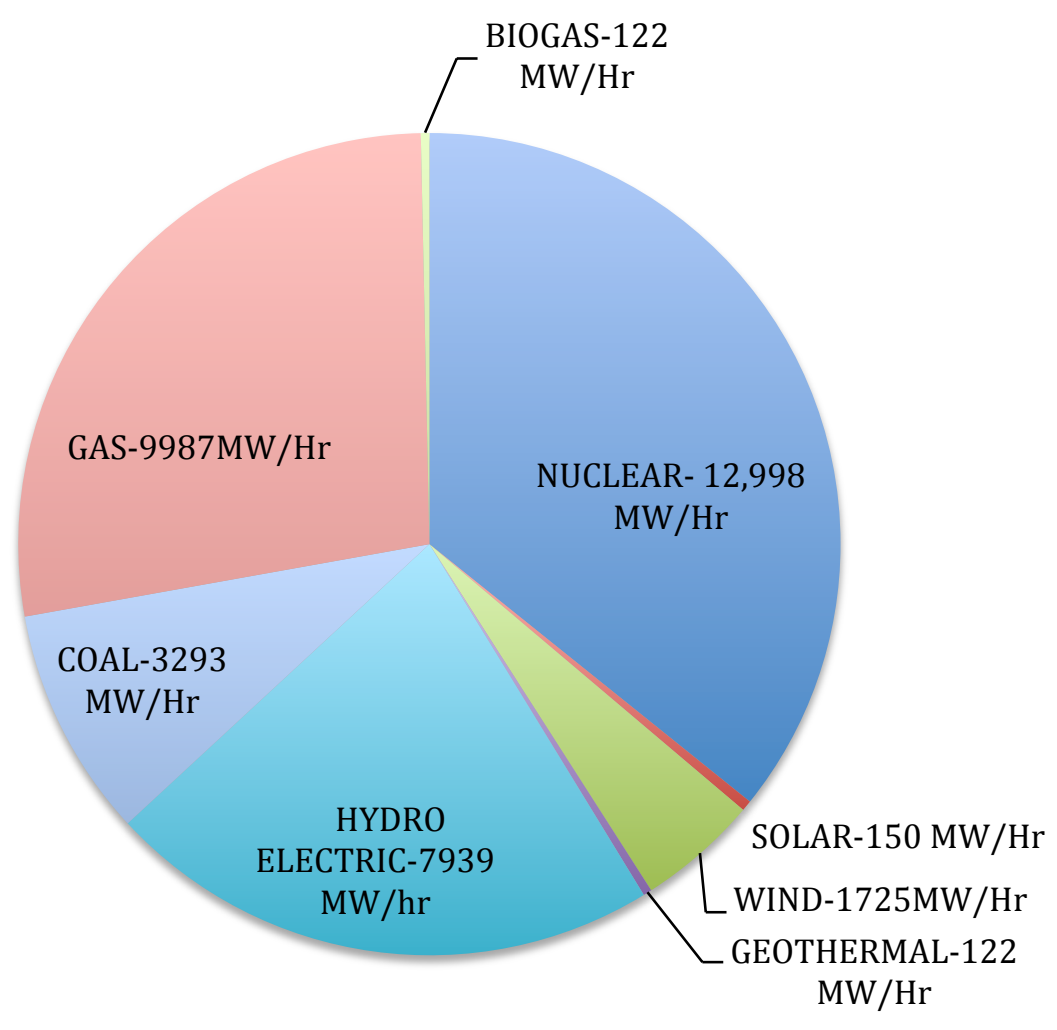

Figure 2.1: Typical generation in Ontario (2012)

\subsection{Types of renewable sources}

Energy is the capacity of a physical system to perform work. It exists in several forms such as kinetic energy, mechanical energy, heat/light, potential energy and electrical energy. Renewable sources can be attained by an environmental source that can be naturally replenished or reintroduced within an individual lifetime, i.e. it is a sustainable source of energy. The renewable energy source contains commercial and environmental benefits and demerits. Sources like water, sun, and wind do not have a risk of diminution from their use for energy generation, however for biomass, the rate of utilization should not exceed the rate of generation. We can acquire renewable sources from the energy, products and systems for the fossil fuels. The old renewable technologies such as solar energy, wind energy and hydraulic energy have been used in a wide range throughout the world. Currently, renewables are 
perceived not only as a foundation of energy, but also as a gear to address many other pressing needs, including: improving energy safety; decreasing of health and environmental effects related to fossil and nuclear energy, mitigating greenhouse gas emissions, enlightening educational prospects, reducing poverty, and increasing gender equality. Canada comprises broad land and diversified layout, which has an array of sources that can provide renewable energy. Renewable energy sources currently provide $16.9 \%$ of Canada's over-all main energy supply. In order to improve the renewable sources equipment, there has been a development by the help of the natural sources available in Canada. Hydroelectricity, being an important source, plays a significant role to supply the energy, and other major sources like wind and bioenergy act as a sustainable contribution [7].

It is well known to the general public that Toronto, compared to other cities in Canada, has very limited sources of natural resources. However, globally speaking, it is better off than other cities in terms of wider selection of renewable resources. For example, the people living in Toronto enjoy the luxuries of the wind resource of Copenhagen, due to the city's proximity to Lake Ontario. Furthermore, it is also well observed in the present day that the wind energy deep rooted in the Ontario Lake has proven to be one of the most economically sustainable energy sources. If Toronto is compared with Southern regions, it can be noted that Toronto has better solar resources than Germany and Miami as the air conditioners in Toronto work better even during the extreme hot season of summers [2].

If we look at Ontario's electricity supply which is an assorted combination of different sources, for example, Nuclear, Hydro, Gas, Coal, Wind, Solar, Wood waste and Biogas etc., there seems to be no doubt that because of its excessive need, a lot of pressure is imposed on the electric supply system. The Government is making efforts in Ontario in order to evolve to cleaner and more reliable sources of electricity for one should not put their reliance on lowpriced fossil fuels- coal etc. that might take substantial toll on the air we breathe [8]. 


\subsection{Ontario Long Term Energy Plan}

The Ontario Long Term Energy Plan is truly a remarkable plan for accomplishing the plan set for clean, affordable and efficient energy [9].

This plan is truly designed for the people of Ontario; Ontarians have actively participated and have shown their support to shape the plan that was released in December 2013. Today, achieving balance in electricity generation, the Ontario Long Term Energy Plan represents it best. The five key points in the decision-making process are [9]:

- Reliable

- Cost effective

- More clean energy.

- Community conferences.

- Increase in more community meetings before starting a new power generation project [9].

The renewable energy technologies considered in the energy plan are outlined in the following table [2]. 
Table 2.1: Renewable Energy Sources considered in the energy plan [2]

\begin{tabular}{|c|c|c|c|c|}
\hline Source & Technology & Energy Form & Location & Application \\
\hline Solar & Photovoltaic & Eloctricity & Distributed, Central & $\begin{array}{l}\text { Building integrated, } \\
\text { residential, commercial, } \\
\text { solar parks }\end{array}$ \\
\hline Solar & Thermal - water & Water heating & Distributed & $\begin{array}{l}\text { Residential, commercial, } \\
\text { swimming pools }\end{array}$ \\
\hline Solar & Thermal - air & Space heating & Distributed & $\begin{array}{l}\text { Commercial and } \\
\text { industrial, make up air }\end{array}$ \\
\hline Solar & Passive & $\begin{array}{l}\text { Space heating. } \\
\text { day lighting }\end{array}$ & Distributed & Residential, commercial \\
\hline Wind & Wind Turbines & Electricity & Distributed, Central & $\begin{array}{l}\text { Residential, wind furbines, } \\
\text { wind farms }\end{array}$ \\
\hline Hydro & Water Turbines & Electricity & Central & $\begin{array}{l}\text { Run of fiver, impounded } \\
\text { water }\end{array}$ \\
\hline Geo-Energy & Ground \& Water & $\begin{array}{l}\text { Space heating } 8 \\
\text { cooling, water } \\
\text { hoatinn }\end{array}$ & Distributed, Central & $\begin{array}{l}\text { Residential, commercial, } \\
\text { central generation }\end{array}$ \\
\hline \multirow[t]{3}{*}{ Bio-Energy } & Bio-mass & $\begin{array}{l}\text { Space \& water } \\
\text { heating, co-gen }\end{array}$ & Distributed, Central & $\begin{array}{l}\text { Residential, commercial, } \\
\text { central generation }\end{array}$ \\
\hline & Bio-gas & $\begin{array}{l}\text { Space \& water } \\
\text { hoating, co-gen }\end{array}$ & Central & $\begin{array}{l}\text { Commercial, power } \\
\text { plants, generation, } \\
\text { displacement of NG in } \\
\text { sunply distribution }\end{array}$ \\
\hline & Bio-fuels & $\begin{array}{l}\text { Space \& water } \\
\text { heating, co-gen, } \\
\text { traneportation } \\
\text { tuals. }\end{array}$ & Central & $\begin{array}{l}\text { Commercial, central } \\
\text { generation }\end{array}$ \\
\hline
\end{tabular}

\subsection{Defining Generation Sources}

Renewable sources of energy can be considered environmentally friendly and cause less hazardous effects to the atmosphere. There are plenty of sources of energy that can play their role as renewable foundations of the energy, and provide the environment with a cleaner impact and help to resolve pollution and the sources of pollutants. The mentioned power generation methods can be defined as renewable sources since the sources are not reducing any resources to produce the energy. Renewable technologies can be developed on a large scale and small offgrid applications [7].

Wind energy

Solar energy 
$>$ Hydro power

$>$ Geo thermal

Biomass

Nuclear power

\subsubsection{Wind Energy}

Nowadays, wind energy is being increasingly used to generate electricity. The procedure to generate wind energy occurs by converting the kinetic energy in wind to a useful form of energy. On wind farms, turbines with large propellers are placed in planned areas that have suitable wind systems and that are in range to existing electrical grids. When the wind speed is sufficient to move the blades of the turbine, only then is wind energy captured. The turbines are suitable for moderate wind speed; otherwise they can cause damages if being operated during high winds. Canada has enormous regions with tremendous wind assets and therefore major potential for the expansion of wind-generated power. Some of the utmost eminence areas are offshore and along coastlines [7].

Wind turbines, as discussed above, play an important role in the formation of electricity. For the same reason, an initiative was taken in 2003, on the grounds of the Exhibition Place where a wind turbine in North America was installed in downtown Toronto [2].

A local community group, Toronto Renewable Energy Co-op (TREC), installed the turbine, which was later followed in the wind community as co-op model developed effectively in Denmark and other cities. This project remained an attractive component for the North American "Toronto Hydro", a publicly owned electricity company and for a community based co-operative. Subsequently, with time and along the lines of its dire need amongst the people, it was built as community energy groups in other cities and throughout towns in Ontario [7].

Wind farms that are installed on agricultural farmland or grazing areas have the least environmental effects of all energy sources. Due to the rapid increase in technology, wind 
energy has doubled from 1.5\% from its previous production between 2005 and 2008. In 2008, in numerous countries it had reached a fairly high level of penetration, accounting for electricity production of approximately $11 \%$ in Portugal and Spain, 19\% in Denmark and 7\% in Ireland and Germany. Europe leads the world in development of offshore wind power in 2008, due to shallow waters and strong winds in the Baltic Sea North Sea [7].

To produce significant quantities of powers, it is important that wind generators encapsulate both- the high wind speeds and "laminar" wind flow. It is important because wind machines, particularly the smaller sizes, are not generally considered practical in the settings or urban areas as these sizes in an open space horizontally on the ground that leads high above the ground. There has also been a development in terms of the wind generators that are especially designed for the urban settings. These wind turbines are specifically designed for higher buildings. The international media has its eyes on this new development of energy turbines and soon it will be a development in almost all urban cities where there is an immense needs to save the state of energy and power crunches. However, on the other end, it is important for Canada to be sure about its laws and regulations that will ensure the use of the energy turbines. The Government needs to ensure that the local regulations that relate to wind turbines are not in conflict with the power source regulation [2].

\subsubsection{Solar Energy}

Solar energy is derived from the energy of the sun in the form of radiated heat and light. It can collect directly from the sun store in the form of thermal energy. The radiant energy from the sun can be utilized to provide heat and power to commercial and residential areas. Solar energy technologies can be used during daytime and only if sunlight is not prevented by clouds, buildings etc. Typically, these engage the considered site of the buildings and several components of these buildings, such as windows, overshadows and thermal masses. They can be considered advantages for lighting and space heating to drastically lower the usage of electrical or mechanical equipment [7]. 
There are two types of solar technologies that contain mechanical or electrical equipment. The solar collectors or panels are usually used to heat the water or ventilate the air for the usage in the households or the buildings. The other technology such as solar photovoltaic technology utilizes the use of solar cells to convert sunlight into electrical power. One of the rapidly growing sources is Photovoltaic (PV) currently being developed by the countries [2].

\subsubsection{Photovoltaic: Electricity from the Sun}

Another development in the file of production of electricity is to make the use of Photovoltaic (PV) modules. These modules play a role to transform the solar energy into heat and electricity. For the last ten decades, Canada has been eminent in producing electricity by means of steam technology that would involve nuclear coal and natural gas stations. This practice has remained the same and no new development with regards to PV modules is implemented in Ontario. The city needs to cater the needs of residents and importance of PV modules as it would help the country economically and has also gained a lot of attention in interacting world as a symbol of the cost-saving equipment [2].

The significant use of PV modules can be seen from its immense appreciation from the international world as for over the last decade there has been an annual growth rates exceeding 30\% and prices dropping 3-5\% annually for the last 20 years. By the next decade, there will be new projections on terms of production of PV electricity that will be marked as a significant symbol to generate electricity by large non-renewable power plants [2].

Solar cells have become more transportable, resourceful and even adaptable, permitting for simple installation. Solar cells have been used to power applications that range from small to medium-size [7].

\subsubsection{Hydro Power}

The phenomenon of flowing natural water in rivers offers kinetic energy to convert into usable energy. The usages include the mechanical energy for alteration activities such as milling, sawing and for irrigation. Rivers are being used for several purposes such as transportation (e.g. moving logs from the forest zone to the industrial area). Hydropower is a major form of usable 
energy that is currently being produced from flowing water. The process of producing hydroelectricity is through turbine blades, which are kept moving by the flow of water, causing the blades to spin, in turn causing the electrical generator to spin and create electricity. The projects produce no waste once the hydroelectric complex is constructed. In distant areas, smallscale hydro or micro-hydro power has been rapidly growing as a renewable energy source. The installation of micro-hydro power has no discernible environmental effect. Small-scale hydropower system does not use the dam water or major water diversion, but rather uses water wheels to produce the electricity. This was roughly $19 \%$ of the world's power, increase from $16 \%$ in 2003), and represented in excess of $63 \%$ of power from renewable sources. While numerous hydroelectric undertakings supply public electricity networks, some are made to serve particular industrial enterprises [10].

One fascinating probability that was specified amid the meetings is the capability of water collecting from the highest points of high structures. The long haul capability of this possibility could be investigated further [2].

\subsubsection{Geothermal Power}

One of the finest ways to extract energy is the geothermal energy process; it extracts energy naturally through the earth and can be used on a miniature level such as residential units or as a geothermal heat pump, or on a much larger scale such as energy production through geothermal power plant. This process is cost effective, consistent and environmental responsive,

but has been geologically restricted to areas that contain tectonic plate boundaries. Through current technological developments it has intensely expanded the size and range of viable resources, particularly for direct applications such as residential heating. It requires no consumption of fuels and is resistant to the instabilities in the fuel cost, but the capital cost tends to be high. Exploration of resources and drilling entails high financial risks. Currently geothermal power has been generated in 24 countries around the world and has many international sites that are being constructed. It offers sustainability: a large geothermal plant can supply power to the entire city while the smaller plants can supply to the rural areas or individual residence [10]. 


\subsubsection{Bio Energy}

Bio-Energy is one of the most significant resources, which is imminently available. However, in Toronto there is limited capacity to use bio-energy especially related in the usage of waste streams. In Toronto, the energy produced from the organic materials is significantly smaller in quantity as compared to the other potentials of renewable energies for example Geo Energy, Solar Energy etc [2].

It is important to exploit the additional potentials of bio-energy so that in near future it is used as a replacement of other natural gases as an on-demand thermal energy source. Therefore, to build the unique infrastructure of bio-energy, its merits should be looked closely for it is now considered as one of the most valuable energy sources all around the world especially in urban settings and developed countries [2].

\subsubsection{Bio Gas}

Biogas has been used in Toronto for a long time. The landfills sites for methane gas capture and generation of electricity since mid 1990s are recovering $50 \%$ of methane that the site produces. It can be imagined that Biogas will one day uproot natural gas as the essential source of thermal energy in Toronto [2].

In considering Biogas, there are three technical regions, which can capture the production of methane: Solid Wastes are captured in handling of the wastewater, landfills, or the processing of wastewater [2].

In Europe, US and China there are progressing pilot ventures where crops, particularly developed for their production of methane and quality, are utilized to dislodge regular gas to run co- gen frameworks for power and heat. In California PG\&E has reported an association with the farm industry to give methane that will run a pilot creating plant of $10 \mathrm{MW}$. Also there is ongoing exploration, especially in Europe, on the most proficient method to infuse methane into the natural gas pipeline framework to diminish dependence on characteristic gas [2]. 


\subsubsection{Bio mass}

Biomass has been one of the oldest energy generation source used in Toronto, and usually the usage of biomass includes pellet stoves and wood stoves. There have been no authentic sources on sales or installation capacity of biomass but local stakeholders consider pellet stove popular in the usage. The technology of biomass can be referred to as a renewable source. The procedures occur with living or dead biological material that can be useful as a fuel. Biomass usually refers to plant matter that is grown to produce electricity (E.g. matter like: dead trees and branches, wood chips biofuels). Biomass can include biodegradable waste, which can be burnt and used as fuel. Industrial biomass can be produced from variety of types of plants, such as sugarcane, miscanthus, poplar, corn, sorghum, willow, hemp, switch grass, and a diverse number of tree species, ranging from oil palm (palm oil) to eucalyptus. The plant used for the production of the energy is used for the processing of the raw material. It is a sustainable technology and is growing rapidly in the world [10].

\subsubsection{Nuclear Power}

Nuclear power is considered an energy source that is designed to extract usable energy from the atomic nuclei energy through controlled nuclear reactions; nowadays this procedure occurs only through nuclear fission reactions, though there might be chances to use nuclear fusion and radioactive decay. The reactor heats up the water, forming steam; later on it is converted into the mechanical work to generate the electricity. There are approximately 439 nuclear power reactors working throughout 31 countries around the world. Nuclear energy is a sustainable energy source that reduces carbon emission in the atmosphere and increases the energy by decreasing the dependency on the oil industry. Reviewers consider nuclear power as a possibly hazardous energy source, with decreasing amount of nuclear energy in power production, and despite these risks can be reduced through the new technology. Nuclear power manufactures essentially no air pollution, in comparison to the viable alternative source from fossil fuel [10]. Ontario's main source of energy is considered to be Nuclear, the generation capacity and the demand is changed according to the nuclear sources and the amount of energy generated by a plant. Nuclear reactor plants are located within Ontario in Pickering, Darlington 
and Bruce power stations, which are considered to be safest, and they use Uranium in CANDU reactors (Beck \& Martinot, 2004).

\subsection{Barriers to Renewable Energy Technologies}

Renewable energy technologies have an immense prospective in the upcoming future energy necessities of the world. The study indicates the future of renewable energy by having voluminous customers purchasing the renewable power even if the cost is somewhere more than conventional power. These energy barriers include cost and pricing barriers, legal and regulatory barriers and market performance, although it can be categorized into four types [11].

- Commercialization barriers- challenged by the new renewable technologies, which are competing with the settled energy technologies.

- Price distortions- from current subsidies and unsatisfactory tax liabilities between renewable energy sources and other energy sources.

- Market performance- breakdown of the marketplace to assist the civil/public settlements of renewable energy sources

- Market barriers such as insufficient knowledge, lack of capital access, "split incentives" between tenants and building owners, and high transaction fees for small purchases [11].

\subsubsection{Commercialization Barriers:}

To compete with the nuclear technologies and fossil fuel, renewable energies must overcome two predominant obstacles to commercialization: immature infrastructure and the lacking of economies of scale [11].

\subsubsection{Infrastructure:}

Large initial investment would be required to build a new renewable resource. Such investments will increase the fees of providing renewable electrical energy during the early period of development [11]. 


\subsubsection{Economies of Scale:}

The renewable energy technologies are developed on assembly lines, where mass manufacturing can significantly decrease the expenses. Economies of scale are also expected to indicate the cost declines for fuel cell, wind, and biomass technologies. Unfortunately, as long as relatively few products are being produced, prices will remain high. This problem will lead to low demands and therefore allow for low production volumes [11].

\subsubsection{Unequal Government Subsidies and Taxes:}

Fossil fuels and nuclear technologies have an advantage in terms of government support for research and development as compared to renewable energy technologies. The receiving aids for research and development, established producing technologies have a lower tax liability. The taxes of revenue and estate are higher for renewable sources; they need large amounts of capital investments but have a lower fuel and operating costs. The tax burden for wind energy is almost as high as for biomass [11].

\subsubsection{Market Barriers:}

Renewable energy technologies come across significant barriers in the markettransactions [11].

\subsubsection{Lack of Information:}

Consumers may have unsatisfactory knowledge to make the choice for adopting renewable sources. Most companies deliver less or no knowledge about their emissions or the fuels they use. The renewable technologies are comparatively new, so the consumers have less knowledge. Buyers, for instance, may feel that solar and wind innovations are untrustworthy because they are accessible only in the daylight or when the wind is blowing. They are unrealistic, and one needs to be mindful that these discontinuous innovations can be exceedingly reliable when consolidated with different alternatives [11]. 


\subsubsection{Institutional Barriers:}

Business and industrial clients are likewise new to renewable energy sources and have institutional obstructions to obtaining renewable vitality sources. Modern vitality supervisors are prepared just to discover minimal effort arrangements. Industrial environmental managers search for approaches to reduce in-house pollution and are unrealistic to consider pollution connected with their electricity purchases. Indeed nearby power organizations may be new to renewable vitality sources. Most utilities have not examined how renewable assets could fit into their frameworks or what neighborhood assets are accessible [11].

\subsubsection{Small Size:}

Renewable energy sources ventures and organizations are relatively small. Consequently they have fewer assets than extensive organizations or incorporated utilities. These small organizations are less able to correspond specifically with high numbers of clients. They will have a lower clout posing positive terms with large business players. What's more, they are less able to participate in regulatory or authoritative transactions, or in industry discussions characterizing new power market sector standards [11].

\subsubsection{High Transaction Rates:}

Small developments have high exchange costs at numerous stages of their development cycle. Case in point, it costs more for monetary organizations to assess the credit-value of many small projects than of one vast project [11].

\subsubsection{High Financing Costs:}

Renewable energy source developers and clients may experience issues acquiring financing at low rates so it can be accessible for traditional energy facilities. Aside to having higher transaction costs, budgetary establishments are unfamiliar to the new advances and prone to see them as unsafe, so they may loan cash at higher rates. High financing expenses are particularly critical to the competitive position of renewable energy sources, since they generally 
oblige higher introductory ventures than fossil fuel plants, despite the fact that they have lower operating expenses [11].

\subsubsection{Transmission Costs:}

Renewable vitality sources might likewise be charged higher transmission costs than routine advances or may be liable to other unfair grid approaches. For instance, a framework that obliges generators to reserve a block of capacity in advance may force a discontinuous generator, like wind or solar, to pay for the maximum yield they can produce at any minute. More often an irregular asset produces at less than its potential limit. Since a wind farm produces just around a third of the time, it would need to pay three times more for every kilowatt-hour transmitted than a conventional plant intended to create at full limit capacity all the time. Another issue is foreseeing the precise time and amount of force for delivery, since wind velocities or daylight can be hard to anticipate more than a day or two ahead of time [11].

\subsection{Cost of Electricity in Ontario}

Cost of electricity in Ontario is varying a lot. This is only due to Time-of-Use (TOU) rates. For better understanding Time-of-Use rates have been divided into 3 different categories. These 3 different peak categories usually help to better understand the power consumption and also to save on electricity bill. Electricity prices also vary in summer and winter times. Ontario Energy Board is regulating cost. The following are the 3 categories [12].

Off - Peak: Generally in off-peak the demand is very low. Majority of the household in Ontario use electricity in their off peak hours [12].

Mid - Peak: Usually, this cycle occurs in daytime and demand of electricity is moderate [12].

On - Peak: This is one of most important cycle when the demand is at highest. Generally, this happens during the daytime when everything is in use [12]. 
Generally, the Ontario Energy Board applies rates to consumers but if the consumers are linked with different electricity companies, the rates that are set by the board do not apply to them. Moreover, by looking and better understanding of our bills we will be able to save the cost of bill and also electricity [12].

\subsection{Typical Demand in Ontario}

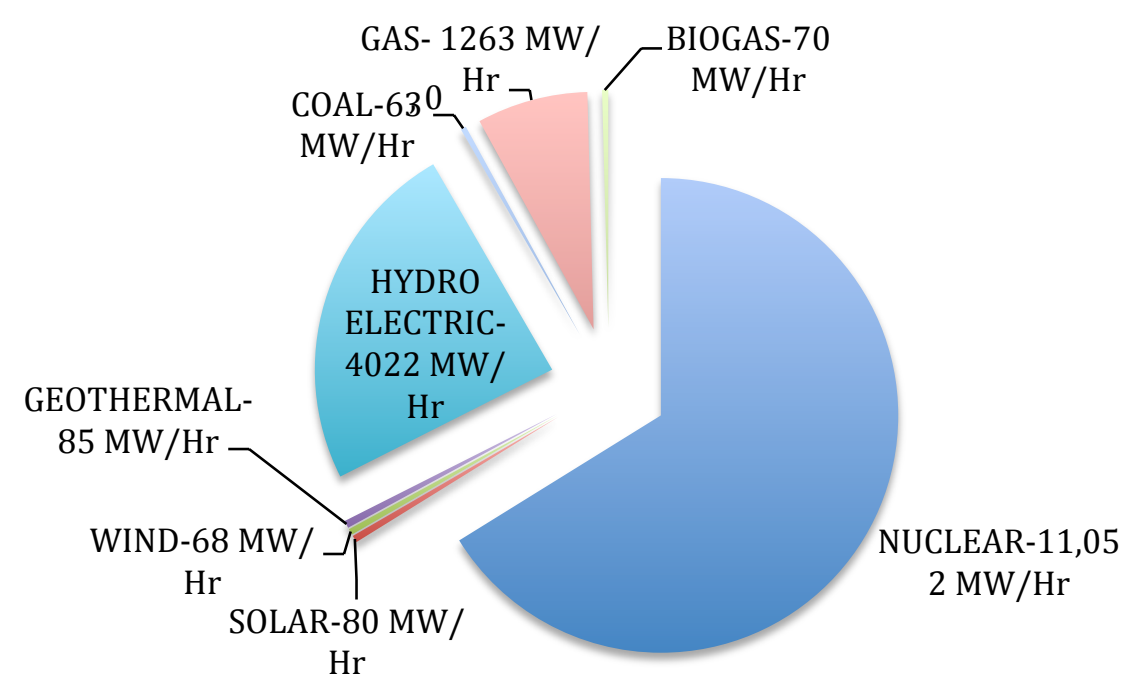

Figure 2.2: Typical Demand in Ontario-2012

The typical energy demand of Ontario is $16,703 \mathrm{MW} / \mathrm{Hr}$. Nowadays the demand of energy is rising. We would need a range of energy sources for future electricity generation and the demand. Although we need to keep this reason in mind that one of the main goal of electricity generation in this province is to reduce GHG (Greenhouse Gases) and the harmful toxics in the environment. The above figure explains the demand of the energy in Ontario and is divided with respect to the renewable sources. If we compare the Generation and the Demand of Ontario (Figure 2.1 and Figure 2.2), we can clearly see that Ontario is generating more electricity than is needed, because the nuclear plants produce electricity $24 / 7$ and the other electricity sources thus making our energy high. This creates surplus energy for the province. One example of surplus energy was in spring 2014 when the selling of electricity at a negative price occurred 
and there was a decrease in demand of electricity due to mild weather as the customers chose to use neither heaters nor air conditioners, so electricity was generating at its own normal scale, thus creating a surplus. In order to get rid of that, Ontario had to sell the electricity to its counterparts Quebec, Michigan, and New York at a negative price. We need to focus on our generation in order to balance our demand for electricity [13].

\subsection{Distributed Generation in Toronto}

\subsubsection{Distribution Planning \& Transformation}

In Ontario, Planning of transformation and distribution of the power supply have played a vital role for Ontario to make the best use of electricity. This practice is going on from decades and by the time passes; we have new and more efficient Distributed Generation, which is being introduced in the system. Transformation and Distribution have been assembled together in light of the fact that both bottlenecks are connected and must be connected together to form another transformer station. It is very important to determine the exact location of transformer station for various reasons. Firstly, it should act as the key to the heaps it serves to minimize misfortunes along feeder lines and in addition the expense of running those feeders. Furthermore, there must be a sufficient supply of high voltage energy to a transformer station to guarantee it can run smoothly at its install capacity [14].

\subsubsection{The DESN Station}

"Dual Element Spot Network" or DESN is an idea that gives excess as duplication for most station segments. There are two approaching transmission lines, two transformers and two low voltage busses. Any of these parts can fizzle without genuinely influencing supply dependability, as the sidekick hardware is equipped for conveying the aggregate station load. The structure of a DESN station is demonstrated as follows. The dotted lines demonstrate that either incoming transmission line and fellow transformer can supply either low voltage transport [14]. 


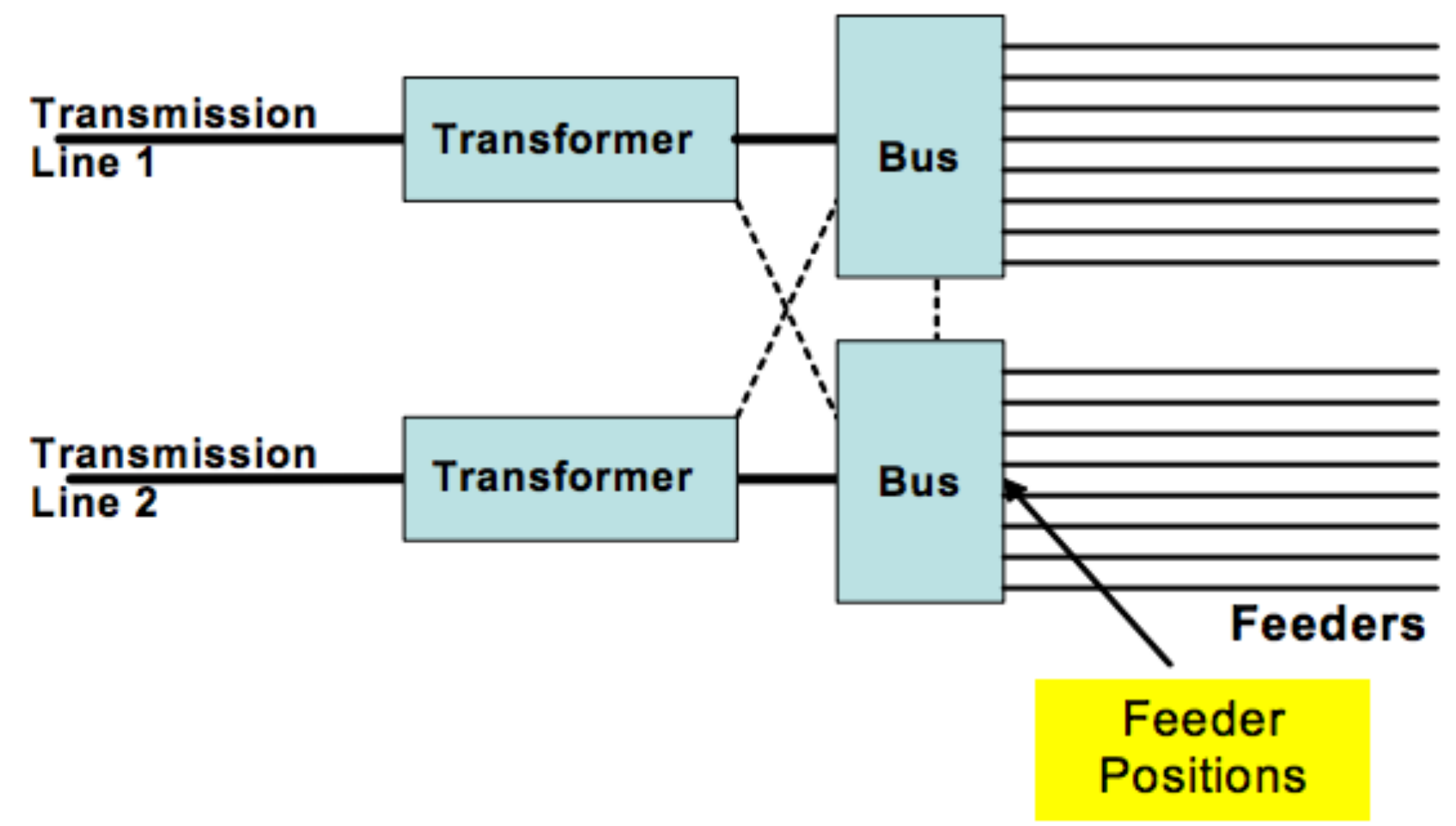

Figure 2.3: The DESN Station

There are approximately 260 DESN transformer stations in Ontario. These stations have the capability to take high power from high power voltage transmission lines. They can take $115 \mathrm{kV}$ or $230 \mathrm{kV}$ power load and step it down by using transformer and able to supple approximate 8 outgoing low power feeders. Some of these low voltage feeders are usually $13.8 \mathrm{kV}, 28 \mathrm{kV}$ or $44 \mathrm{kV}$ pole line that can easily carry power along normal pole that can be easily installed on the side of the roadways and they contribute power to desired communities [14].

\subsubsection{The Distribution Network}

There are two different types of distribution networks currently working in Ontario. One is the urban area and another one is the rural area. The rural areas distribution networks are the simplest and are easily connected with a network of feeders, and everyone has their own independent power supply load range, which is from 15 to 22 megawatts. There is no excess in rustic regions and to the supply station encounter a disastrous disappointment, if the radial feeder 
failed for any reason, it directly affects the consumer and power outage will occur. This is a general risk that is neglect able and has to accept. This is due to that repairs are easily available in wood pole as compared to other poles and is usually completed in hours and it also helps to prevent the total failure of power stations [14].

Generally in urban areas they follow different design from the rural areas. The feeders are connected with each other so that they interconnect with power station. This type of scenario is easily possible because feeders are connected closely to each other. These types of arrangements allow shifting the load with in the feeders system and also in between the power station so overloading situation can be prevented. The essential capacity of low voltage feeders is to convey energy to ranges where new advancements are occurring and to meet the demand that is a prerequisite where existing load is developing. It is truly conceivable that even in a region where the total load is staying steady or declining there will be a necessity to assemble feeders to supply stack development neighborhoods [14].

According to a census report, the City of Toronto has a population of approximately 2.7 million and the power demand supply is approximately $4000 \mathrm{MW}$. Toronto Hydro is the company behind the maintenance of the supply, distribution and transformation system in Toronto. The approximate number of customers in Toronto Hydro is around 800,000. The peak load in the city is approximately 4800MW. With two main high power transmission lines passing through the city, Toronto hydro has approximately 238 supply and transformation stations and also around 60,200 transformers distributed across the city [14].

Power generation is typically distributed in Toronto power lines and some grids. Although, $60 \%$ of power consumption is being consumed by Residential and remaining $40 \%$ is consumed by Commercial. The total $60 \%$ of the power is residential but it has been divided into some categories which is town houses, residential building, hospital, Offices, Governments buildings, Community Centers and Transit. The Commercial sector generally consumes power in Industries, Malls and Shops. 


\subsection{Consumption in Toronto}

Power consumption in the City of Toronto is one of the highest in Ontario. There are many reasons for this; as we know, Toronto's population is estimated to be around 2.7 million and an epicenter of business and travel. In this report, we are focusing only on renewable sources. We would like to see how power consumption is going on in Toronto if we just focus on renewable sources. We already know there is more generation then power consumption in Ontario. By just taking the numbers for renewable sources we are able to generate the following table.

\begin{tabular}{|c|c|c|c|c|c|c|}
\hline Renewable Sources & $\begin{array}{c}\text { Hydro } \\
\text { MW/Hr }\end{array}$ & $\begin{array}{c}\text { Solar } \\
\text { MW/Hr }\end{array}$ & $\begin{array}{c}\text { Wind } \\
\text { MW/Hr }\end{array}$ & $\begin{array}{c}\text { Geothermal } \\
\text { MW/Hr }\end{array}$ & $\begin{array}{c}\text { Natural } \\
\text { Gas } \\
\text { MW/Hr }\end{array}$ & $\begin{array}{c}\text { Bio Gas } \\
\text { MW/Hr }\end{array}$ \\
\hline Avg. Generation & 4567 & 115 & 112 & 120 & 2122 & 122 \\
\hline Avg. Consumption & 4003 & 75 & 69 & 84 & 1254 & 65 \\
\hline $\begin{array}{c}\text { Total daily } \\
\text { requirement }\end{array}$ & $\begin{array}{r}\mid 7 \\
\text { Avg. available peak } \\
\text { consumption }\end{array}$ & $4237 \mathrm{MW} / \mathrm{Hr}$ \\
\hline
\end{tabular}

Table 2.2: Generation and Consumption rate of Renewable Sources in Toronto

The table shows us a general representation of generation and consumption through renewable sources. Usually in Toronto the peak time varies based on the. There is also peak time consumption in the daytime according to power generating companies. According to IESO, the peak time requirement for Toronto is around $4805 \mathrm{MW} / \mathrm{Hr}$. While doing our research; found that Toronto needs approximately $4237 \mathrm{MW} / \mathrm{Hr}$. Further research reveals that installed power plants are not operating at their full capacity; they are usually operating on half or $75 \%$ of their desired capacity. This gave us a good knowledge that our generation is higher but overall consumption is relatively low. Our generation is calculated in Megawatt per hour (MW/Hr) from all the plants that are operating in Ontario [5]. 


\subsection{Typical Electricity requirement in Toronto}

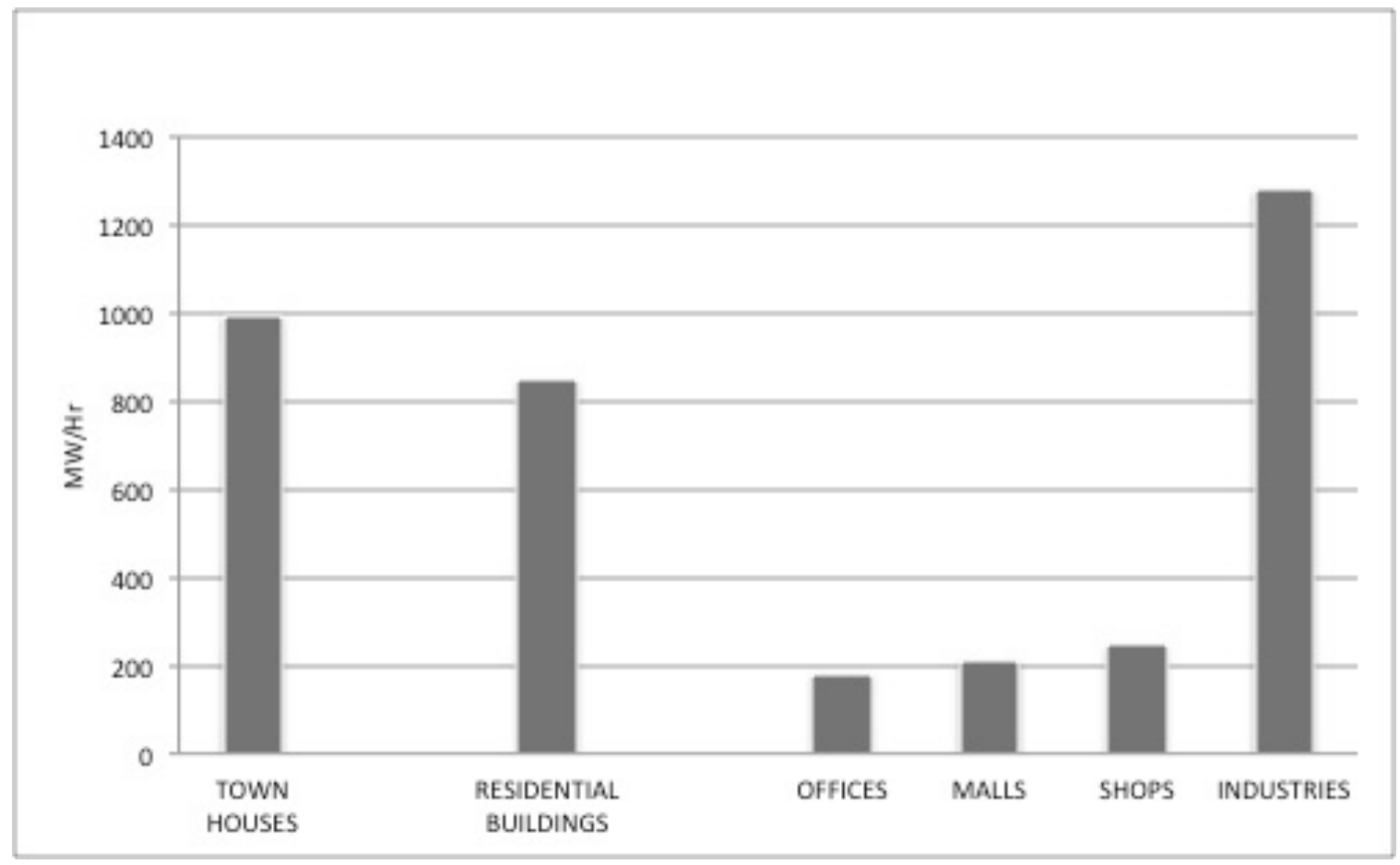

Figure 2.4: Categorical distribution of electricity in Toronto

We have further divided electricity demand in Toronto into categorical distribution. The categories can be understood by examining figures 2.4 and figure 2.5. Currently we have examined 14 categories, which covers the major consumption parts in the city. The charts explain the typical requirement of town houses in Toronto, which is approximately $991 \mathrm{MW} / \mathrm{Hr}$., which includes single and semi-detached houses and duplexes etc. In Residential buildings the approximate electricity requirement is $846 \mathrm{MW} / \mathrm{Hr}$., which includes high and low-rise buildings and condos. Offices require $182 \mathrm{MW} / \mathrm{Hr}$., which include private and corporate buildings in Toronto. Malls like Eaton Center, Fairview Mall and Yorkdale Mall etc. have requirements around $212 \mathrm{MW} / \mathrm{Hr}$. Whereas shops include all the local market shops, convenience stores etc. have requirements of approx. $246 \mathrm{MW} / \mathrm{Hr}$. and industries require a greater amount of electricity supply at $1277 \mathrm{MW} / \mathrm{Hr}$. 


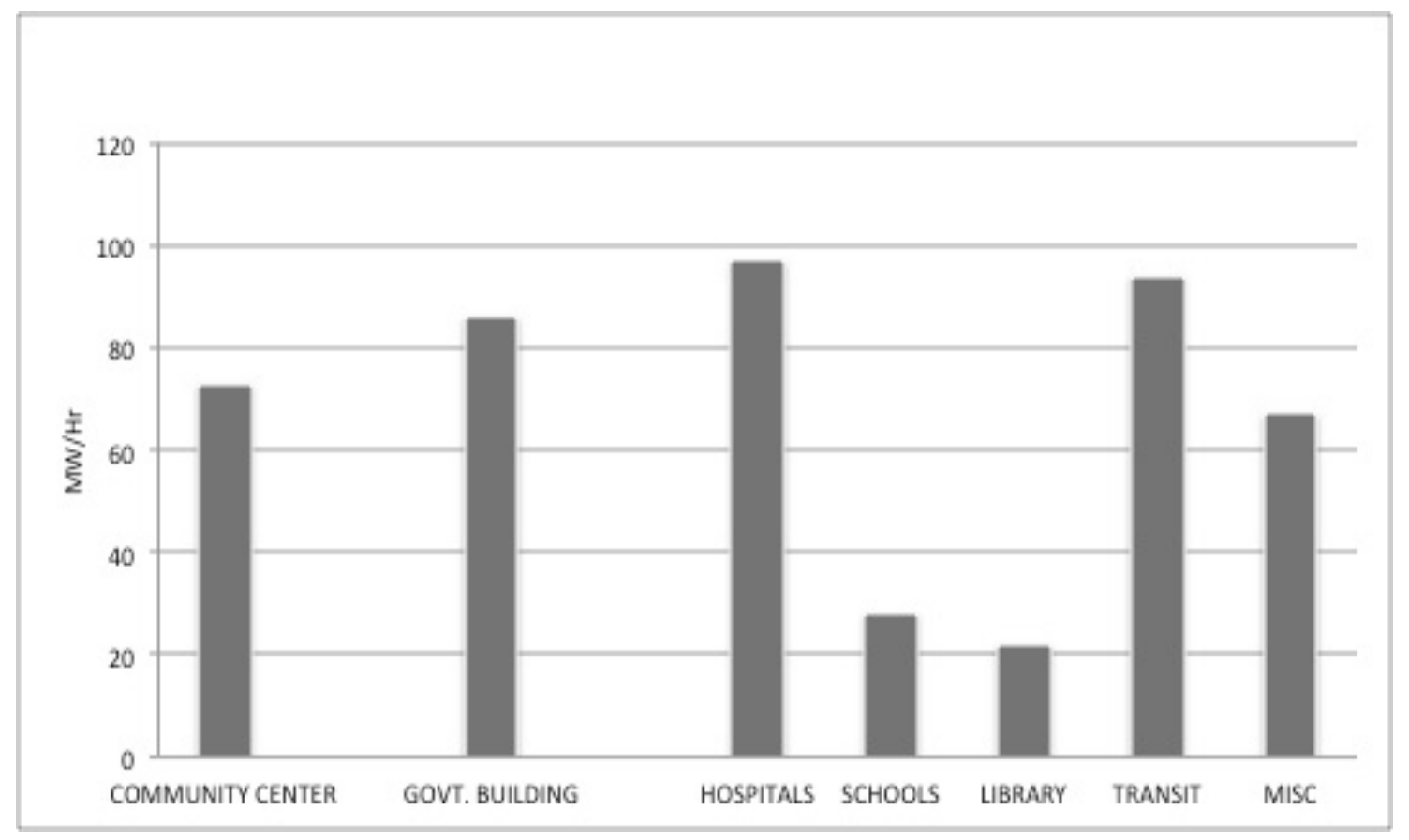

Figure 2.5: Categorical distribution of electricity in Toronto

In this graph we further discussed the requirement of electricity for community center which is approximately $73 \mathrm{MW} / \mathrm{Hr}$. It is comparatively low compared to the above graph because most of the community centers operate around $9 \mathrm{am}-5 \mathrm{pm}$, whereas there would be only a few of them which function at night to provide shelter. Government buildings include the Service Ontario Center, municipal buildings and Government of Ontario buildings etc. which usually require approximately $86 \mathrm{MW} / \mathrm{Hr}$. Hospitals consume approx. $97 \mathrm{MW} / \mathrm{Hr}$. There are approximate 600 schools in Toronto which operate on general timings of 8:00 am-4:00 pm, and their requirement of electricity usage is approx. $36 \mathrm{MW} / \mathrm{Hr}$. There are about 113 Toronto Public Libraries in our city, which require about $30 \mathrm{MW} / \mathrm{Hr}$. The Toronto Transit is used by 2.6 million people living in Toronto and completely relies on electricity in order to operate and provide better service for the citizens; its electricity requirement is $94 \mathrm{MW} / \mathrm{Hr}$. Now the last category was named "miscellaneous" and includes bars, hotels, tourist places like CN Tower, Ripley's Aquarium, Art Gallery of Ontario etc. They require approximate $67 \mathrm{MW} / \mathrm{Hr}$. 


\subsection{Benefits of Distributed Generation in Toronto:}

\subsubsection{System Benefit}

\subsubsection{Reduce Peak Demand}

The need and requirement of the transmission and distributed systems during peak hours needs to be reduced in order to be responsive and available for back-up power during some emergency grid breakdowns and outages [15].

\subsubsection{Potential for DG to Reduce Peak Load}

Having known that it is not a good practice, DG has evaluated a number of utilities by its use to reduce the demand when load is at its peak. Quite a many techniques have been used for these evaluations. Some methodologies use specific data for substations and feeder lines while others are observed to have generic information. A good example is defined over here.

DG is found to be the most financially appealing choice in a few of these evaluations while in others it is not. In the cases where DG is assumed to be the most appealing choice financially, not always it is necessary to have large investments made in DG. There are a number of issues responsible for this such as unfamiliarity with technologies related to DG, its equipment tools, methodologies and techniques. It is also believed that investments done in traditional T\&D equipment will cause less controversy with cost recovery [15].

\subsubsection{Reduce line losses, Increase system efficiency}

Amendments in power flows that flow along the distribution lines often affect the system losses. If power generation will be done on-site, it will help in cutting down the system losses due to reduced demand of power on the system. The exported power of a distributed generator might tend to reduce system losses if it is placed near a large load, in contrast to which if remotely distributed generators export power to the grid, they will likely increase these system losses [15]. 
The International Energy Agency has reported that DG's widespread deployment could save up to 30 percent of the total expenses of electricity by lessening the distribution and transmission losses and expelling the extravagant infrastructure [16]. One of the greatest plus points of DG is the highly decreased transmission loss and/or a powerful reduction of wastage of electricity in the electric power transmission along long distances. In the United States the losses of transmission and distribution were at 7.2\% of total electricity generation in 1995 [17]. On the other hand, the Ontario Clean Air Alliance makes a guess that the overall system losses in Ontario was at an average of 7.5\% [18] precise data is not yet available.

\subsubsection{Environmental Benefit}

DG has been observed to be comparatively less troublesome and less messy and polluting than central generating stations. It is recommended to pursue neat and clean DG options and technologies, for example solar TV etc. that will be highly beneficial for environment. In the development of DG, we see natural gas playing a vital role. CHP is found to be playing particularly more important role being less carbon intensive than other fossils, thus resulting in higher conversation and greater efficiency of DG [19].

\subsubsection{Reduce carbon footprint, Lower GHG emissions}

Gas emissions in a greenhouse can be cut down in a number of ways by DG. A few of those are listed here: through higher efficiency and better performance, by deployment of clean renewable energy and also through demand management. It is likely to be seen that it will expedite the move away from much centralized and polluting plans to rather small and local generators. The overall reduction of GHG emissions around the province can be greatly facilitated by CHP at industries by cutting down the need and demand on coal fired generation. Along with its energy supply needs, CHP is observed to have an integral role in accelerating the climate targets of Ontario [19]. 


\subsubsection{Increase the amount of clean energy}

The development of DG having been deployed across the board is assumed to have an extremely important role in speeding up the renewable energy deployment, by the respondents hence achieving green energy targets. This kind of relates to previously the system bias and system change that was mandatory to promote a move to less centralized generation. This system change was raised by over 50 percent of the 19 citing this specific benefit. This boundless system change was not seen by many as something mandatory or resulting from greater uptake of DG. This shift to DG, providing a system change ensures more clean deployment of energy, erasing a few of the bias system and comparative costs over time [19].

\subsubsection{Reduced fuel consumption}

Greater efficiency creation is ensured by DG as observed by many respondents. According to a few, as time will pass, powerful and obvious devaluation in fuel consumption will be observed together by these symbiotic benefits through greater individual control and generator. More awareness of consumption and supply by individuals and community; higher efficiencies through the system; and comparatively larger conservation [19].

- Respondents have observed the system benefits of DG to be of the highest priority followed by environmental benefits, which are then followed by social benefits and lastly the economic benefits [19].

- The stakeholders and collaborates highly understand, appreciate the influence and advantages of DG. It is also evidenced by the strong individual support of various respondents in interviews [19].

- DG provides an enormous range of benefits. These benefits at the moment are sometimes not sufficient enough to speed up any vast implementation of DG. This is because of the very low penetration of DG observed and witnessed in Toronto or Ontario [19]. 
However, the Province's goals of change in climate and weather conditions, energy, development of community and sustainability are seen to have been aligned closely with the observed advantages of DG. Currently, the cost or incentives for DG and cogeneration projects do not reflect these values. The playing fields are altered towards central generation, hence segregating against local and smaller generation [19]. 


\section{Methodology}

The scope of this report is to study the power requirements of Toronto, Ontario. Through this we are able to examine the main categories where there is a good number of power consumption. We will give a look on the different categories as well as their consumption timings and their peak load consumption. From which, we can explain the power trends that are generating in Toronto.

Currently, our energy system is unstable and is old. In order to examine the system carefully we need to study electricity requirements and consumption trends. Meanwhile, our city is focusing on renewable energy sources such as wind, solar and nuclear etc. Currently, the electricity requirement of Toronto is approximately $4237 \mathrm{MW} / \mathrm{Hr}$ and the peak load is approximately $4805 \mathrm{MW} / \mathrm{Hr}$. Since electricity is a type of energy that can't be adequately put away bulkily, it must be produced, disseminated, and expended instantly. At the point when the load of an energy system hits the maximum producing capacity, system administrators should either discover extra supplies of energy or discover approaches to shorten the load, known as load management. If the load shortens or exceeds the normal capacity the energy system will become unstable and power outages will occur in the city.

The scope of this study is to focus on load management as well to study the peak load timing so that we have an adequate knowledge of the power consumption data. Firstly we will start by explaining load management of the City of Toronto, and secondly we will discuss the peak time electricity in certain hours of the day.

Demand side management (DSM) is commonly known as Load Management. This process is generally used to balance the supply of electricity by adjusting the electrical load in the network by not putting pressure at power station. Since we know load management allows utilities to change the demand for the required electricity in peak hour timing. It can eliminate by reducing the need for power plant. Also, if peaking of power plants is unable to control, there are major chances that power plant will go overload and unexpected power outages occur. Since backup generator and peaking plants are mostly less efficient and are old compared to base load 
power plants, load management helps them to decrease harmful toxic gases in environment; currently, the techniques of load management are still being developed by government and private sectors [20 \& 21].

In the City of Toronto, the peak load s different in summer and winter. We will generate graphs by looking into the peak load of all categories and will understand the load management. We have taken one residential house consumption data; also, we are gradually shifting our focus to residential assessment area where we have divided our residential data's value in per residential house unit. Our main goal of this survey is to understand the load management of one residential house, which consists of all the daily electronic appliances and general family members that utilizes them, by looking at the load management in per unit residential unit.

In our study we distributed load management in the below flowchart. Through the data of the electricity consumption of these stated categories, we are studying the requirements and peak loads of the electricity so that we can predict the trend of electricity in order to stay ahead to deal with the problems related to energy systems. Further on, we have described each category in detailed manner in terms of peak load time at different hours in a day and figured out how the trend of electricity is generating in the peak hours of the day and evening. 


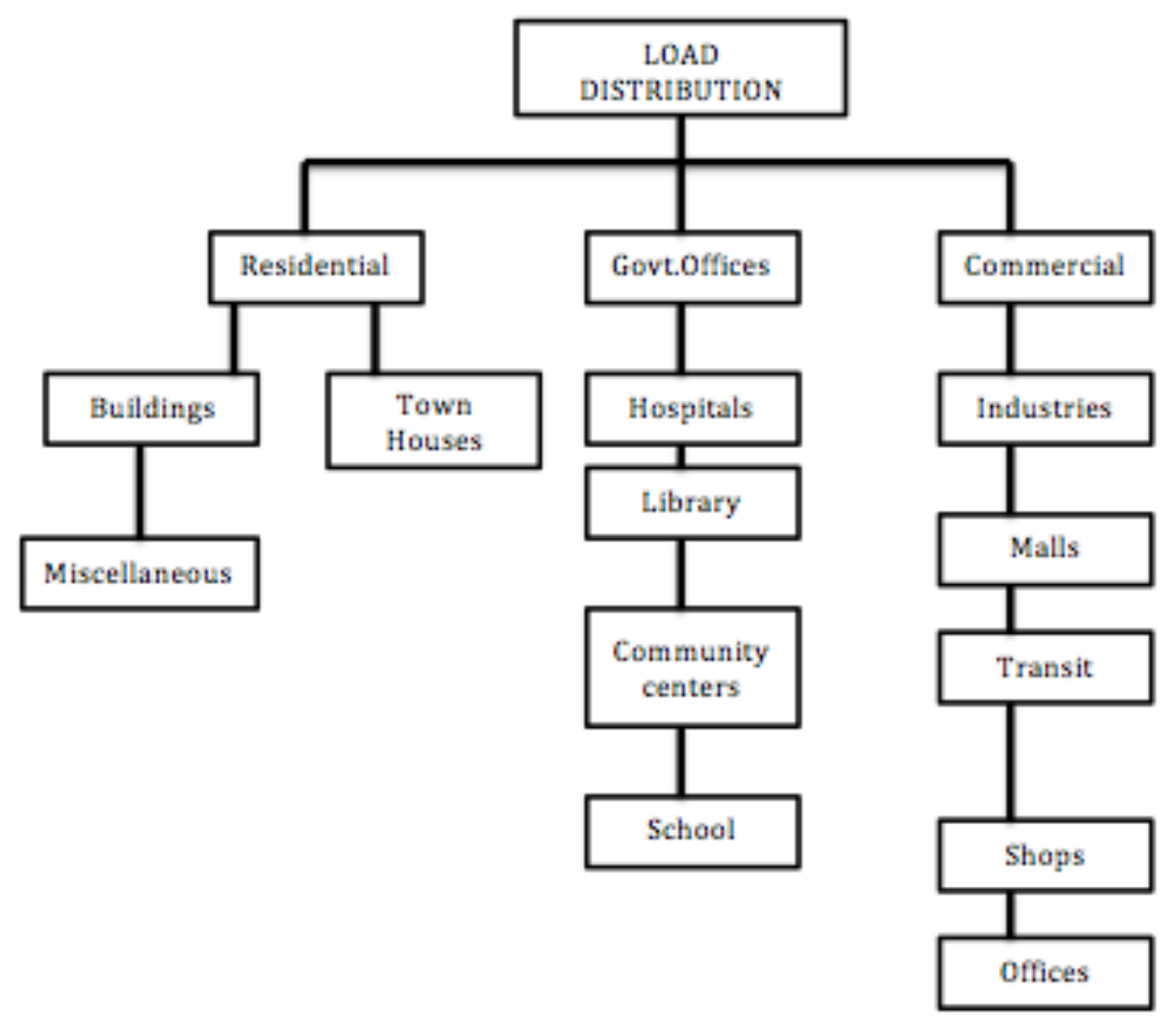

Flow Chart 3: Categorical distribution of load distribution

The graphs of the consumption rates have been generated by using IESO (The Independent Energy System Operator). The main feature of IESO is to maintain the balance between supply and demand of the electricity throughout the province; it also plans to fulfill the need of Ontario's electricity grid and is responsible to set the electricity price in the market. The data has been gathered from this platform and we have looked over past two years (2012 and 2013) of electricity's supply and demand and peak timings of consumption [5].

After collecting the data, our main focus was the categorical distribution of electricity load in various places. To monitor the electricity loads at specific timings we have visited these sites several times for months in order to generate the peak-load graphs, which are discussed further in the discussion section. 


\section{Discussion}

In this chapter, we have conducted a survey of various energy consumption sources and distributed the electricity consumption data categorically.

\subsection{Town House Assessment}

Toronto has one of the most influential real estate currently. The prices of townhouses are constantly changing day and night. This real estate industry is filled with different type of houses from average small town houses to big multimillion-dollar mansions. Cost of living is getting higher day by day in Toronto. People are finding new and cheaper ways to cut down costs. Even in the power-consuming trend, people are building new ways to cut down their monthly bill and they are also generating their own power supply for their daily needs.

Nowadays technological advancements in power generation have changed the world. We can develop our own electricity for the requirement. If your electrical generation is increased, you can easily sell to the power generation companies in your area. This will reduce the cost of bill and will be more environmental friendly.

In the City of Toronto, there are approximately 195,000 housing units. These include single, semi-detached and detached houses. Most of the houses are old. Newly built houses are consuming more daylight as compared to old constructed houses. Also, new homes are generating their own electricity by Solar system or small Wind turbine that can easily install on their rooftops. A typical 3 bedroom house generally consists of TV, Refrigerator, Microwave, Air Condition system, Heating systems, Dishwasher, Washer and Dryer, Stove. The weather is very challenging in city of Toronto. City can have very mild weather and sudden extreme wind chill temperature. In this case, heating and cooling system plays an important role especially in summer and winter times. 
Our electrical load is approximately $991 \mathrm{MW} / \mathrm{Hr}$ and the general number of town houses is 195,000 . This is due to the presence of family members at home enjoying their family time. Simple graphs of summer and winter requirements will be able to help to understand the power consumption in townhouses.

\section{Town Houses (Summer)}

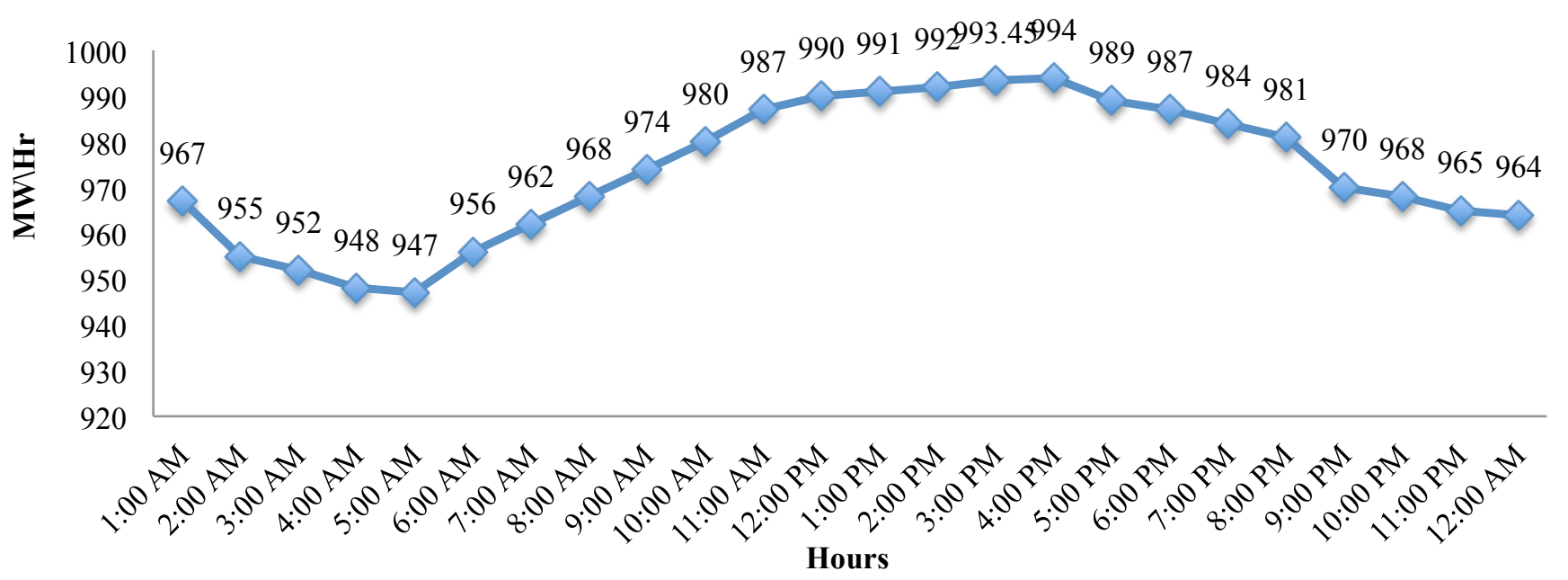

Figure 4.1(a): Graphical representation of electricity requirement in Town Houses (summer)

The above graph is a simple power consumption trend in summer, of town houses. As previously mentioned, townhouses are consuming approximately $991 \mathrm{MW} / \mathrm{Hr}$. however, to explain this graph we will start looking through the time, which is 1:00 am. We can see the power demand is relatively low after midnight, this is generally due to decrease in the consumption of electric appliances but there would be still some consumption due to the HVAC system, and family members are using less appliances during night time. As we see further the peak starts shifting gradually and increases as the clock strikes 4:00 am, which is the time when some Canadian families wake up and start their day. After, the power consumption starts growing as the day passes by. The family members usually leave for work and school around 
7:00 am - 9:00 am; moving further we can see that from 11:00 am -5:00 pm, the peak is quite consistent because of the average consumption rate of electricity during the day. At 5:00 pm the peak starts decreasing gradually and this trend continues till 9:00 pm.

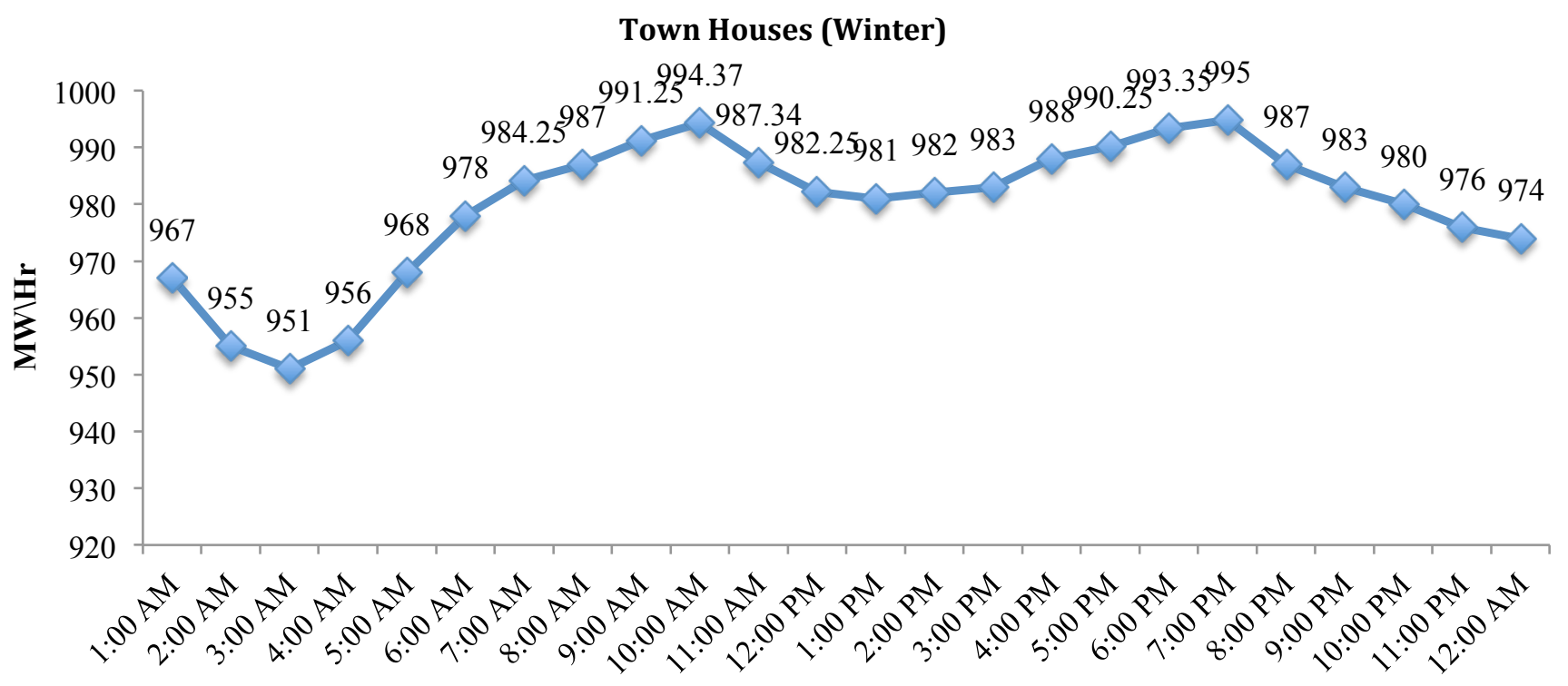

Hours

Figure 4.1(b): Graphical representation of electricity requirement in Town Houses (winter)

In winter, usually there are two peak consumptions. The peak starts to rise around 5:00 am in the morning. From 7:00 am-11:00am the peak stays steady because of the different housework schedule of people. In town houses, residents are able to control the house temperature by themselves, it has been noticed that the second peak usually starts to rise 5:00 pm-7:00 pm. This is generally due to different people are coming back from work at different timing and kids are at home. Somewhere around 6:00 pm most of the family members are at home and they use home appliances for their housework, entertainment and work purposes etc. After 8:00 pm, power consumption starts to decline and this usually happens because people are going for sleep or some are planning to go out to spend rest of the evening with there friends, it 
can be any daily life situation. However, power consumption is usually the same in most of the houses in Toronto; this trend can be frequently noticed in an average-sized family.

\subsection{Transit System Assessment}

Toronto has its own transit system, which is managed by the City of Toronto. The Toronto Transit Commission (TTC) is one of the main transit systems in Toronto, and is responsible for providing transportation system for the citizens of Toronto. The TTC comprises of subways, light rail, streetcar system and buses system. The subway system is one of the main transport systems, and is located in the city to provide an access from one corridor to another corridor. The subway system has four-line systems that are the Bloor-Danforth line, Sheppard line and Scarborough RT that is light rail system. The TTC has launched completely new subway cars that are more efficient; especially they generate low noise pollution.

The streetcar system is one of the main systems that are responsible for providing transportation especially in downtown core. There are number of different lines that are running in another subway station. The TTC has planned to phase out the old streetcars and is launching new streetcars that are more power efficient and accessible for disabled persons. The older streetcars are not too power efficient and reliable.

\section{Transit Assessment}

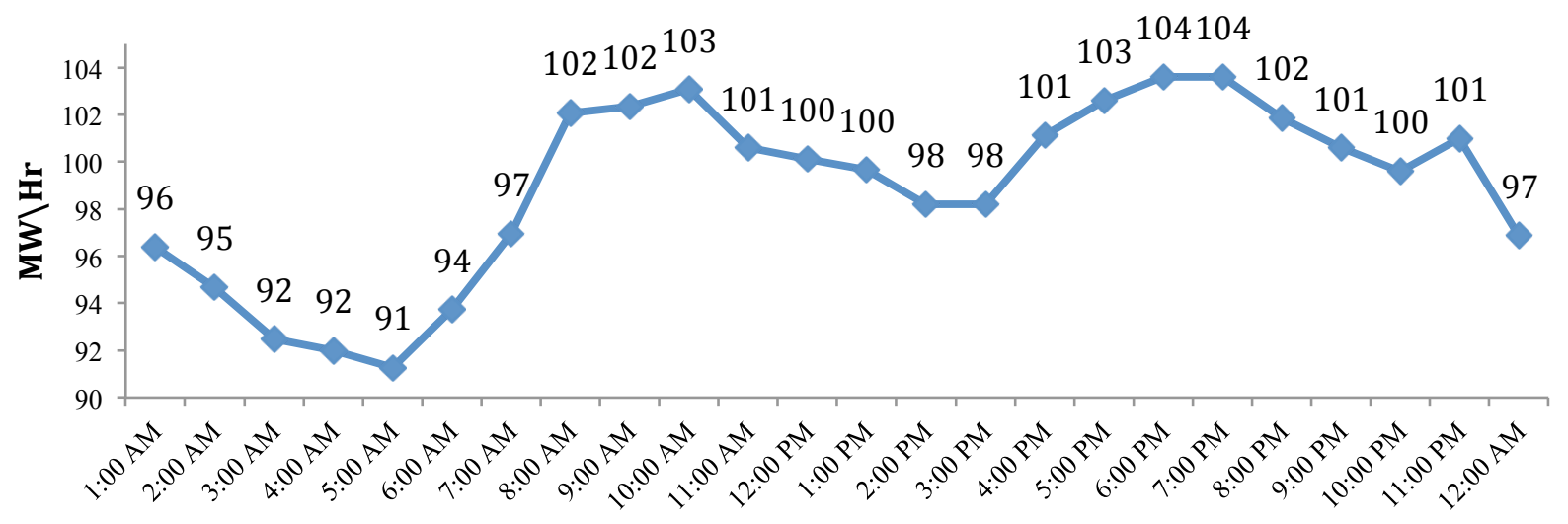

Hours

Figure 4.2: Graphical representation of electricity requirement in Transit System 
Besides all the streetcar and subway systems the TTC has an advance network of bus systems. The bus system helps to cover the rest of the City of Toronto area, which is not accessible by subway or streetcar. Majority of the buses start from the subway stations and end at the next subway system, also providing access to the subway. Most of the buses are hybrid in order to save the fuel consumption and environment friendly. Power consumption of the transit system will take by subway and streetcar systems; they are major areas where most of the power is consumed. There are more than 60 subway stations, with several under construction. The total power consumption by the TTC is approximately $94 \mathrm{MW} / \mathrm{Hr}$. we can see the graph that is divided over 24-hour time line. We noted after the middle of the night the power consumption is relatively low; this is due to no subway service after 2:00 am up to 6:00 am. Then the power starts growing till 10:00 am. This increase in power consumption is due to the morning rush hour. After the morning rush hour is completed, the service starts to become normal. The total time between two subway stations is 4 to 5 minutes and for the streetcar is between 10 to 15 minutes. The evening rush hours usually start from 3:00 pm and continue till 7:00 pm. This is due to different offices hours; schools start to close at 3:00 pm and most of the students use the subway system to travel to their destination. After the rush hours, the subway gradually becomes slow and power consumption starts to decline. The subway closes usually at 2:00 am but it varies at different subway stations. A subway stations starts to open from 6:00 am but again different subway stations have different hours for the first train to pass. The streetcar usually operates 24 hours a day but the service slows down in nighttime. The bus system starts to operate at a night schedule which the TTC calls Blue Night service. This service usually covers the main streets of the city.

\subsection{Government Building Assessment}

Government buildings play an important part in developing the infrastructure of the City. The City of Toronto has a local government system. It has houses of provincial parliament in the heart of downtown. Several government offices include Service Canada offices, Passport Canada and other Canadian government services buildings are in the City. The local government that runs the city is under the supervision of Mayor and its ward members. The famous Nathan Philip Square, which is also known as City Hall, is also located in the heart of downtown. There are 
several civic centers, which are also in the city that come under the City of Toronto administration. Those civic centers are for different types of services and are located in Etobicoke, East York, Scarborough and North York.

\section{Government Buildings}

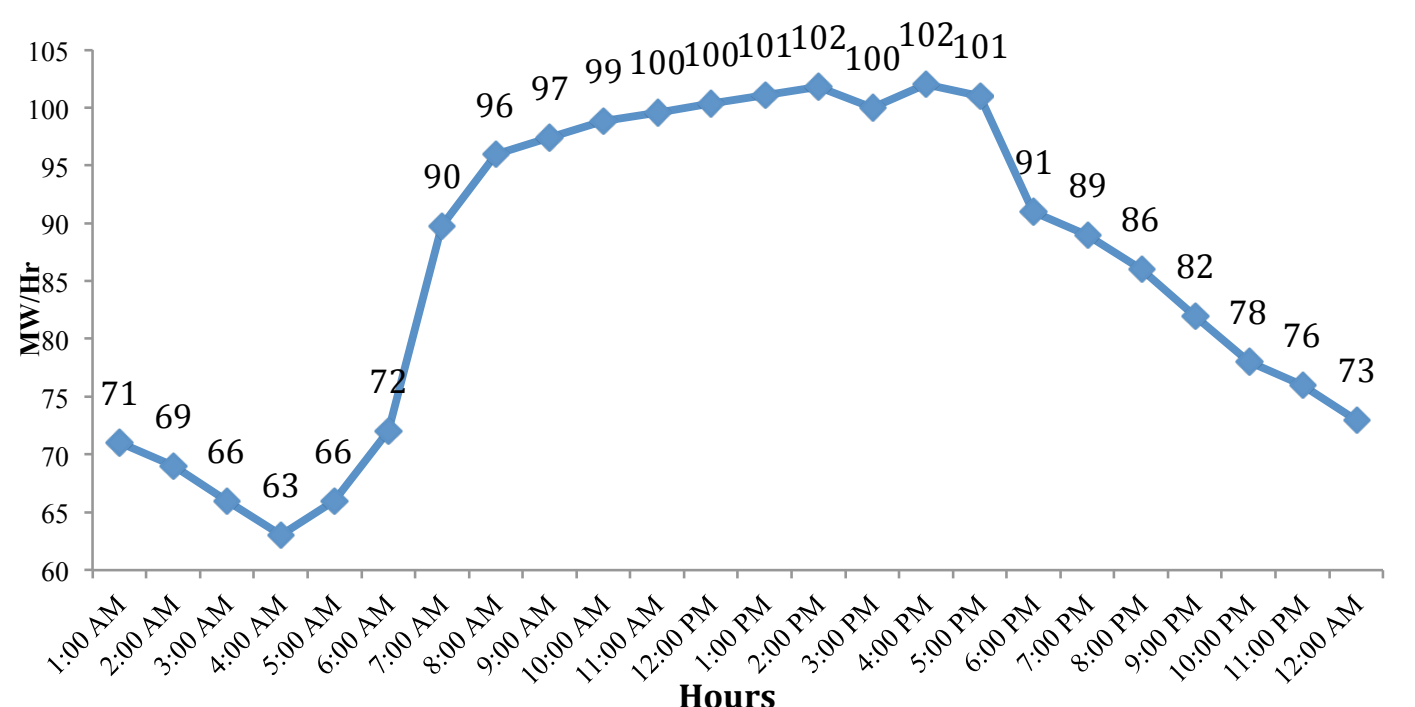

Figure 4.3: Graphical representation of electricity requirement in Government Building

Government offices use less power consumption due to their operating hours, although some government offices are open round the clock and they never shut down. For example, a Police Station, which is also a government office and falls under the city or provincial administration. But in those offices, power consumption reduces due to the amount of staff members. Most of the government offices are operating from 8:30 am to 4:30 pm but as mentioned above, some are operating 24 hours but are not fully consuming the electricity. The City of Toronto has approximately 126 offices in which Municipal offices as well as provincial and Government of Canada offices are also included; we can see a sudden rise in power consumption around 4:00 pm mainly due to the staff members who are trying to finish their work before going home. After 5:00 pm the power consumption seems to start getting normal and gradually decreases through out the rest of the evening. This is basically due to offices closing hours and not enough officials are present in their offices. But we can see there is still power consumption throughout the mid night until the next morning. Government is also planning to reduce the power consumption in their offices. 


\subsection{Community Centers Assessment}

Community Centers are a very important part of any city neighborhood. In the City of Toronto many different cultures exist and they are living in their own community area. These community centers are extremely helpful for the people. Most commonly Community Centers provide services in employment, training in English as a second language, access to Internet and other training services. Nowadays, Community Centers have different people with different languages that spoken to help the people in the neighborhood. There are many different types of Community Centers in Toronto, such as general employment services; services for newly immigrant people, some community have sports complex built in. There are general sport activities, which are offered through community centers, for example, swimming poo;s, health/fitness, basketball courts and play areas for kids.

\section{Community Centre}

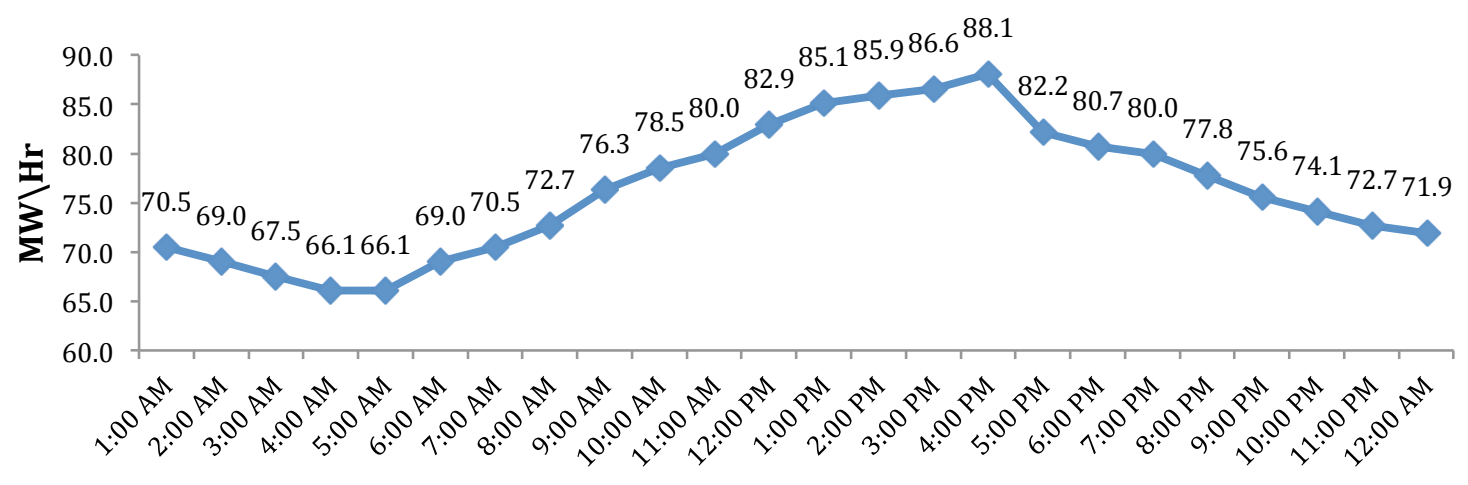

Hours

Figure 4.4: Graphical representation of electricity requirement in Community Centre

In Toronto, Community Centers play an important part in citizens' lives; they bring people close and help to build harmony and peace in the neighborhood, and they plan different events for the neighborhood. In every area, the government has built up a Community Center for citizens; we have approximate 75 Community Centers in Toronto, which serve the neighborhood. Most of the Community Centers operate from 9:00 am to 5:00 pm on weekdays. But some of the Community Centers like the Salvation Army, city of Toronto shelters and some other Community Centers are 
open 24 hours.

The above graph shows approximate consumptions of typical Community Centers in city of Toronto. We can see the consumption trend is increasing at 7:00 am because the community centers start to open in the morning, and it remains gradual throughout the day because of work hours and people attending sessions in the centers, the peak load slightly strikes up at 3:00 pm4:00 pm which is the main hour where people engage in several activities, after that it slowly decreases because people start to wrap up their work and head towards their homes. In the evening and the midnight the consumption rate is gradual in some community centers because of the availability of the shelter to the homeless people, which operates 24 hours a day.

\subsection{Residential Buildings Assessment}

We know that the City of Toronto is very fastly growing There are numerous amount of new projects of residential buildings which are being introduced every year. With lots of new high rise buildings, lofts, small building, every building has its own requirement of power and consumption which depends on every unit and also its tenants. Nowadays, newly constructed buildings are very efficient in terms of power and their design is to use the daylight as much as possible and reduce the power consumption. Some of the buildings have there own power system that is solar. There are some buildings in this city that are generating its own power and it helps to reduce the power consumption in that particular building. Solar panels are installed at roof top of the building in Flemingdon Park Neighbourhood. This type of practice helps to supply power to the tenants of the buildings and it also helps to give some power to the generation system.

We have taken an approximate number of 850 buildings in Toronto that require 846 $\mathrm{MW} / \mathrm{Hr}$ power to tenants. These building include bachelors, 1 bed to 3 bed units. Every unit usually consists of Refrigerator, Stove, Microwave, TV and AC. Nowadays, new buildings also have washer, dryer and dishwasher in their units but they are mostly limited to new residential buildings. Below is the graph of typical consumption system in residential building and they are divided into 24 hour. We have explained the electricity consumption in summer and winter. The peak time and the electricity load vary in these two seasons. 


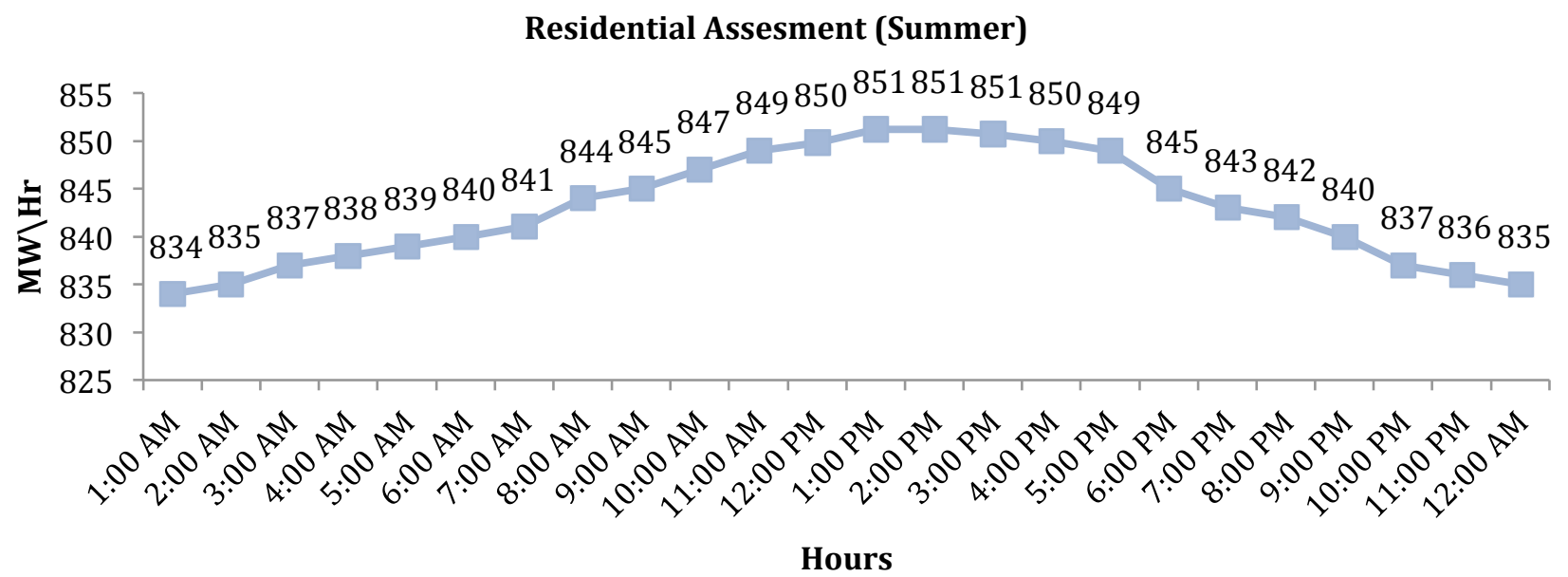

Figure 4.5 (a): Graphical representation of electricity requirement in Residential buildings (Summer)

In the summer time, we can see that from 1:00 am to 4:00 am our consumption rate is relatively low due to less appliance working and mostly people are sleeping. The refrigerators for throughout 24 hours and some lights are left switched on. From 5:00 am to 9:00 am the consumption rate started to increase due to people starting their day and getting ready for offices and kids are planning to go school. Demand starts growing from 11:00 am onwards to 5:00 pm which is mainly because kids come back from school for lunch and in the summer time there are air conditioning systems working all the time to cool down the residential buildings; also people are cleaning their houses. We can see power consumption starts to slowly decline after 6:00 pm is due to people are returning home and they are using different appliances at different timings. After that power consumption starts to decline due to low consumption and people start preparing for the sleep/night time. 


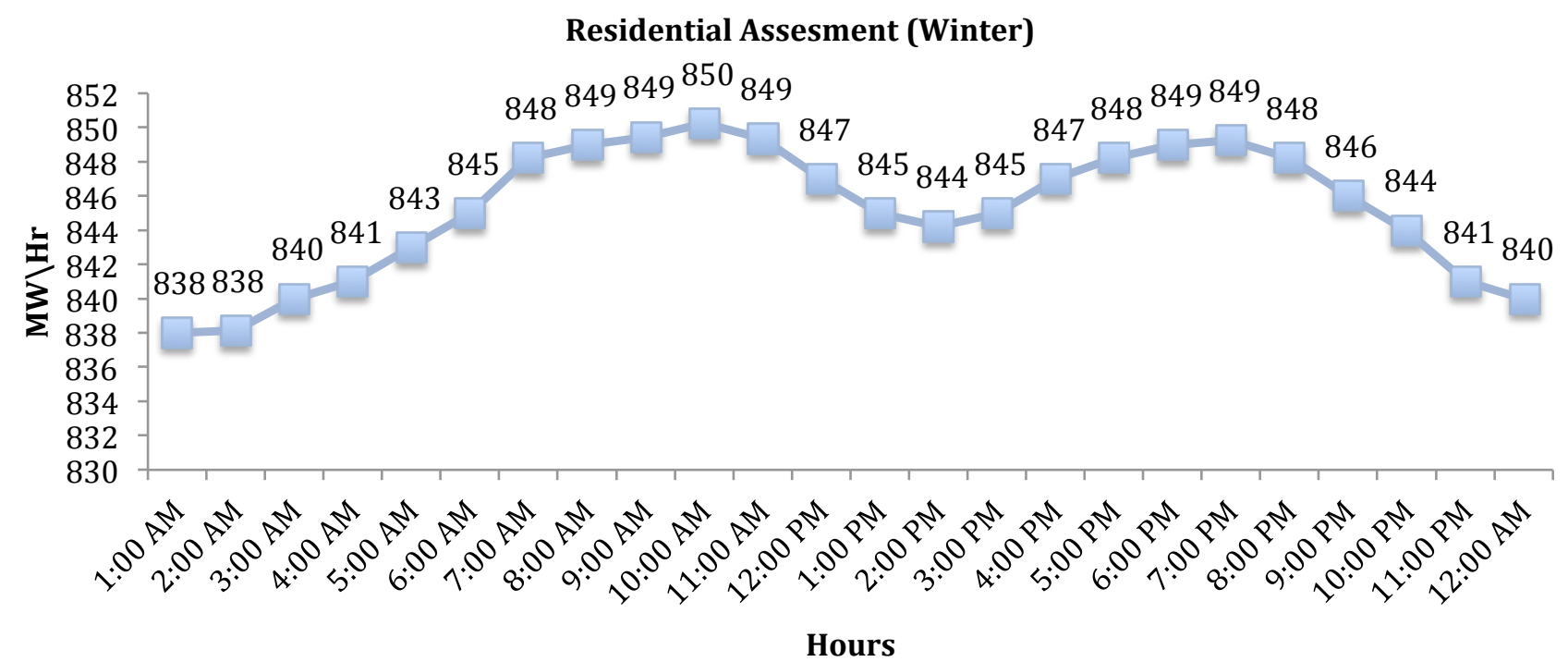

Figure 4.5 (b): Graphical representation of electricity requirement in Residential buildings (Winter)

As mentioned in the graph there are two different peak consumption hours; usually at nighttime the peak is relatively low around 1:00 am till 4:00 am, the consumption rates starts to increase around 5:00-7:00 am in the morning due to people getting up for their work and kids leaving for their schools. The peak starts to gradually grow from 7:00 am till 11:00 am. In winter, heating systems in residential buildings work 24 hours but the heating system is usually set up by a regulator, which controls the heating system of the building w.r.t time and tenants requirement. It has been observed that some of the tenants living in the residential building have their own small heating systems, which they operate according to their needs. Sometimes the consumption rates starts to decrease in the daytime because of the sunlight and better weather, but we can see in our winter graph there is another peak consumption from 5:00 pm till 7:00 pm because people return to their home and they start using different electrical appliances according to their needs. Around 11:00 pm the power consumption starts to decline due to low consumption and people start preparing for the sleep/night time. 


\subsection{Office Assessment}

Growth is a very important factor in making cities famous. The business sector requires office space to work and contribute to the growth of city as well as making one's economy strong. They also help to build a strong image on other cities. In Toronto there are numerous types of offices which range from 1 room space to 50-room space or it could be more than that which depends on the company. Famous offices building in city of Toronto are First Canadian place, TD tower, CIBC building, Scotia bank tower and the list goes on. Most of the office buildings are constructed in a way that they mostly consume daylight. There are some small buildings and have small spaces but these spaces are constructed in a way to consume daylight. They usually consume electricity power. We have selected 750 high-rise buildings and they usually consume $182 \mathrm{MW} / \mathrm{Hr}$. of electricity.

Generally, offices in Toronto have different timings but most start from 8:30 am to 4:30 pm. Some offices start at 9:00 am and end up at 5:00 pm but timing varies and it also depends on the company. Some people finish their work in later hours like after 8:00 pm or close to midnight. In offices we have Air Conditioners, Heaters, Computers and some small kitchen appliances but computers are frequently used during the business hours. In winter timing, we have heating system that runs 24 hours but now they are also temperature controlled and automatically operated when required to save electricity cost. In summer air conditioner runs 24 hours also but they are highly used in daytime during office hours. 


\section{Office Assessment}

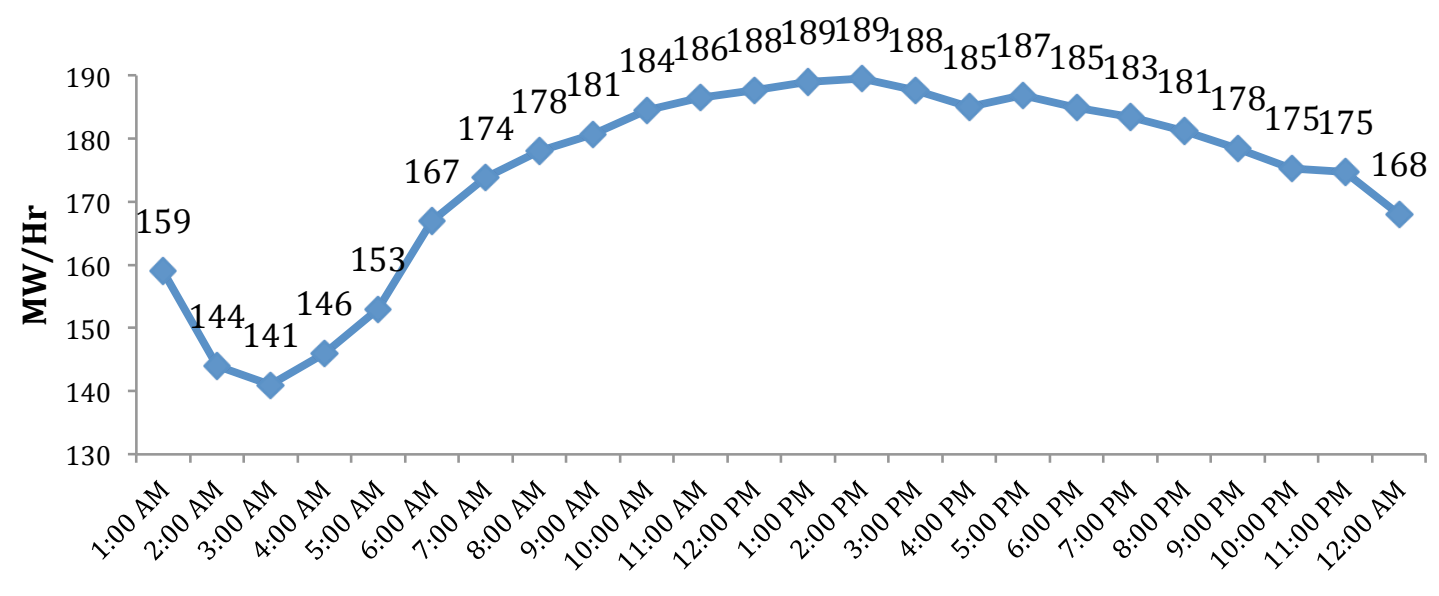

Hours

Figure 4.6: Graphical representation of electricity requirement in Offices

In the above figure 4.6, we have created the same type of condition using the overall requirement that is $182 \mathrm{MW} / \mathrm{Hr}$. As you can see, overall load is relatively low in midnight hours, mainly because no computers are working only some server stations are operating but some of the staff works late hours. At this time usually janitorial services work too. Offices start operating at 7:00 am as some staff start their work in the early morning shifts and the demand keeps increasing till 3:00 pm and then it slows at 4:00 pm due to people leaving their offices but it rises again due to heavy usage of computers and it starts coming down again after $6 \mathrm{pm}$. The reason in decrease in demand at 6:00 pm is because people are mostly finishing their work and some of the staff stays in order to finish their tasks. Janitorial services start in those particular hours and they usually work all night.

\subsection{Hospital Assessment}

Hospitals are an important facility for the residents. There are approximately 123 hospitals in Toronto, which include research facilities, clinics, big advanced hospitals and rehabilitation centers. So the distribution of the hospitals are area wise accordingly which serves a big 
population to the area i.e. if we look at the hospital named Toronto East General Hospital, which is located in East neighborhood of the city is generally used by people living in the east end but it serves to everyone including the people living outside the neighborhood.

In downtown Toronto, there are Toronto General Hospital, Sick Kids hospital, St. Michael hospital and some rehab centers. The government and charities groups operate most of the hospitals in Toronto. These hospitals operate 24 hours and 7 days a week with high facilities provided to the citizens.

\section{Hospital Assessment}

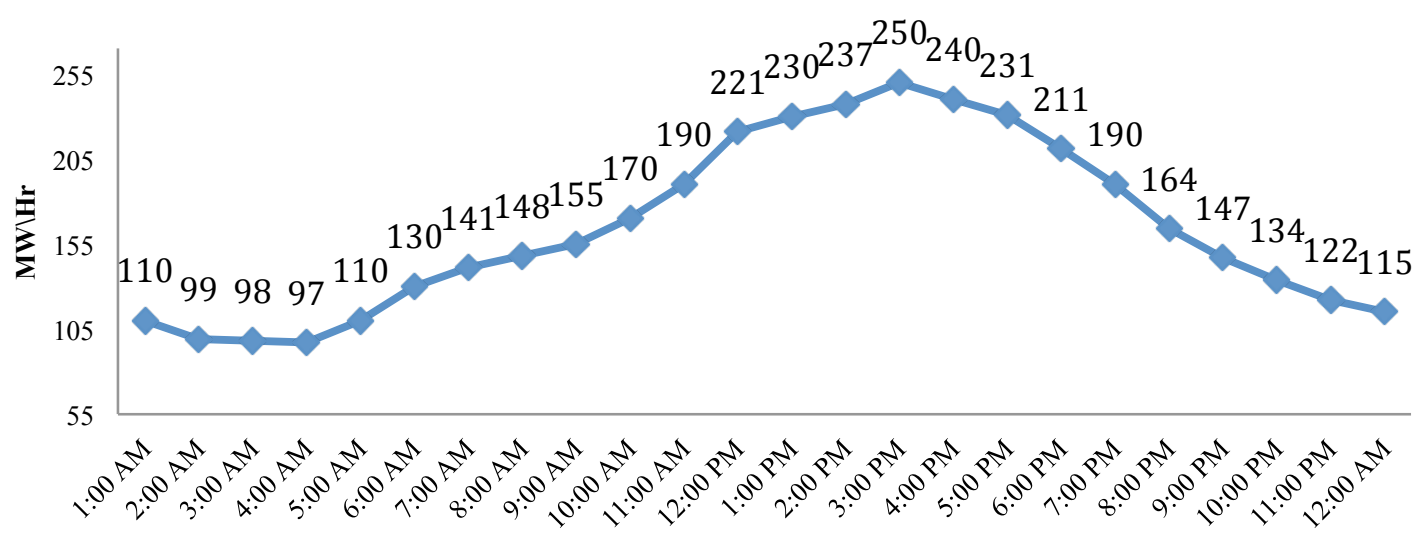

Hours

Figure 4.7: Graphical representation of electricity requirement in Hospitals

Besides all this, we like to shift our focus to power consumption area. Hospitals generally operate 24 hours a day Sunnybrook Health Science center commonly known as Sunnybrook hospital is one of the largest medical centers in Canada and is the second trauma center facility in Toronto after St. Michael's hospital. It is situated on the location where different buildings are being referred as the "Wing". Most of the wings of Sunnybrook are close in evening time except the main building "M Wing' and emergency center which operates 24 hours. Taking the example of Sunnybrook, the power consumption is very low at nighttime and high in daytime. Hospitals in Toronto generally consume $97 \mathrm{MW} / \mathrm{H}$. As you can see in the graph power is relatively low at 2:00 am to 4:00 am is due to low work force at that time. After 5:00 am, power consumption starts increasing slowly and this increase in demand is continued till 5:00 pm. It is a very common factor that many people are working or visiting their loved ones at 
the respective hours. In the evening, people are done from their work shift and they go home which thus causes reduce in demand until the mid night. This power consumption trend is relatively same for other hospitals power requirements as well.

\subsection{School Assessment}

The school System in City of Toronto is one of the largest systems in North America. From world-class university (University of Toronto) to the best private schools, Toronto has many options for education. The Toronto District School Board is of the main school board in Canada with approximately 600 schools monitored under their supervision. Several universities and colleges are located in Toronto i.e. University of Toronto, Ryerson University and York University are the main universities whereas Seneca College (now converted into University), Centennial College and George Brown College are the main colleges in Toronto. With over 200 nationalities and 75 languages spoken in city of Toronto schools, it makes a diverse multicultural intellectual classroom in the various schools and universities [22].

City of Toronto schools systems are very efficient in terms of power consumption. They generally consume $36 \mathrm{MW} / \mathrm{Hr}$ during the daytime only. Although there are few night schools at some universities and colleges, which offer night classes as well, but it does not affect their power requirements. Due to this reason the power consumption at night is low compared to the daytime consumption rate. The graph generally represents the power consumption during daytime and night time of schools and universities. 


\section{School Assessment}

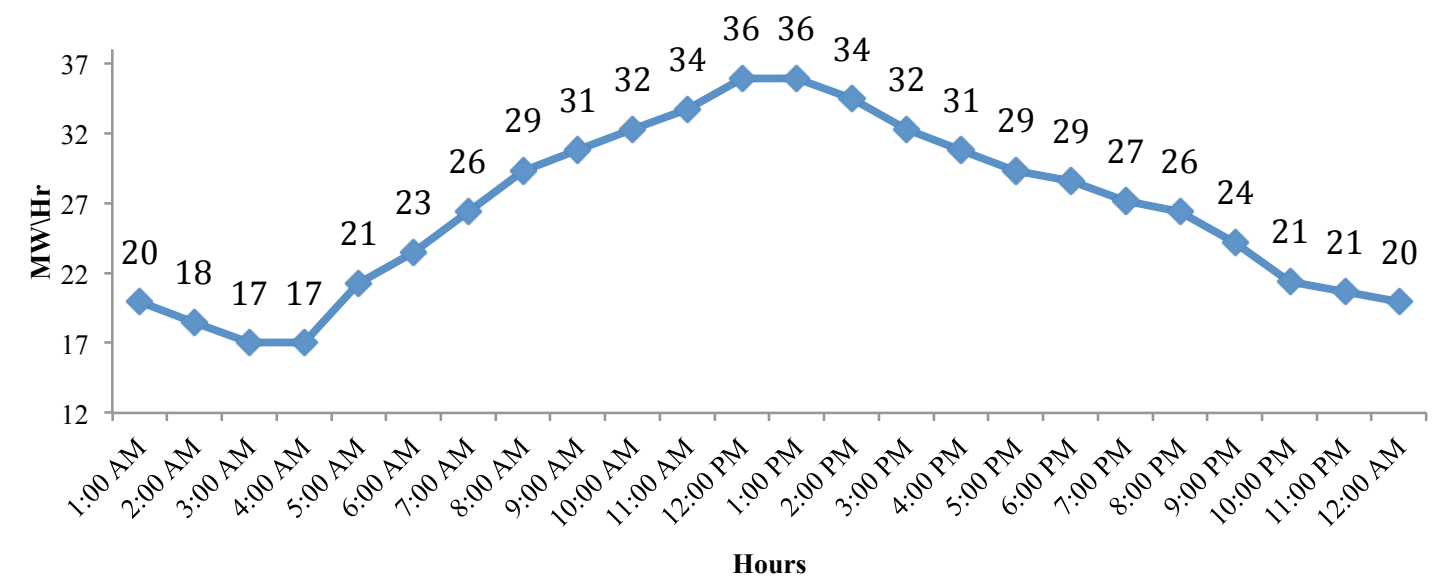

Figure 4.8: Graphical representation of electricity requirement in Schools

According to this graph we can understand the pattern of the power consumption of schools and universities. The peak load is $36 \mathrm{MW} / \mathrm{Hr}$ at 12:00 pm; usually it is the time when the morning classes end and students/teachers have their lunch break. The day starts at 8:00 am in the morning when people start arriving to their desired locations. And as the day passes the power consumption gradually increases their electricity demand. School timings are 9:00 am till 3:00 pm so around 3:00 pm the consumption rate starts decreasing slowly as the day ends. Some of the school power requirement varies due to varying class schedules and night classes but it does not have a major affect on electricity consumptions, whereas the power consumption is usually higher due at the start of the day and gradually increases. There are many schools that operate only in daytime hours. If we consider the power requirements of the universities and colleges they are usually open until mid night but power consumption is relatively low compared to the daytime. After mid night power decreases more which is due to the schools that are closed at night and only janitorial services are operating which require very few watts to operate their equipment for the maintenance purpose. 


\subsection{Library Assessment}

These days' libraries play an important role in the city. As time passes, it becomes a communication hub for the people through new technological advancement in the field of computer and digital services. Currently libraries serve various purposes and are considered more than a place for book reading, which also serves educational training sessions and knowledge sessions for their community members. City of Toronto library is one of the largest systems in Canada. With approximately 113 branches and several other libraries in city, it has become very vital place to study. Some of the best libraries are Toronto Reference Library, Bloor Gladstone Library, Pape Danforth Library, Wychwood and Runnymede Public library.

\section{Library Assessment}

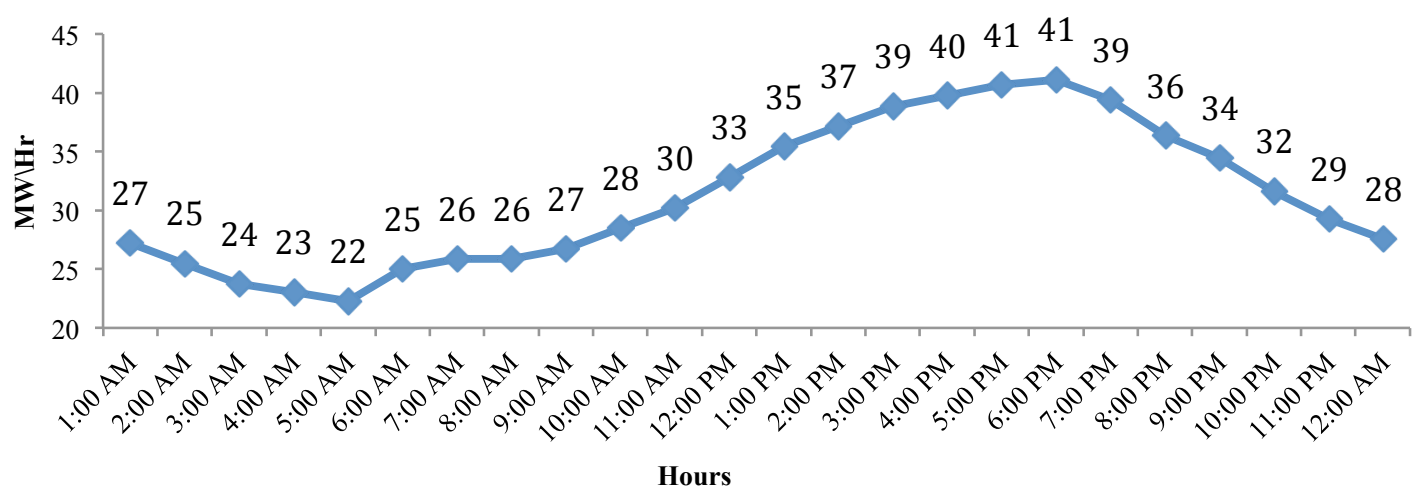

Figure 4.9: Graphical representation of electricity requirement in Library

Power consumption is one of the important factors when it comes to library operations. Most Toronto libraries are operating from 8:00 am to 8:00 pm. The power consumption is relatively low during the daytime but high in evening time. Below is general power consumption of the library system, which consumes approximate $30 \mathrm{MW} / \mathrm{Hr}$.

As you can see in the graph, the power consumption is relative low after mid night until morning. This is generally due to libraries are not in operational hour and majority of the libraries are closed. Demand is getting higher in daytime and gradually increases to $41 \mathrm{MW} / \mathrm{Hr}$ 
around 5:00 pm - 6:00 pm, due to people spending their time in library for their work. After 7:00 pm demand starts to decrease around closing hours, and it gradually decreases to $22 \mathrm{MW} / \mathrm{Hr}$. We can see the lowest power consumption at 5:00 am is $22 \mathrm{MW} / \mathrm{Hr}$ because libraries are generally closed at this hour. Through all this we have seen a general overview in power consumption trend of Library system in Toronto.

\subsection{Malls Assessment:}

Toronto is a great place for shopping as it has a large amount of shopping centers, and a great number of tourists which frequently the city's famous malls. Toronto has approximately 102 shopping malls in which we have 80 finest shopping malls. These include famous downtown shopping mall "Toronto Eaton Centre". This is one of most frequently visited malls. There are several more famous shopping malls which include Yorkdale Shopping Centre, Fairview mall, Sherway Gardens and Scarborough Town Centre. Beside all this, Toronto has hidden underground pedestrian tunnels, which are commonly known as the PATH system. This is a great way to cut across from one place to another in downtown only. The PATH system has everything from flower shops to big Canadian banks as it interconnects with the financial district in the downtown core. That's cross-section of the best Toronto has to offer, beside all this there are plenty of choice for the enthused shopper like shops at Don Mills, Centre point Mall or Woodbine Centre [23].

\section{Malls Assesment}

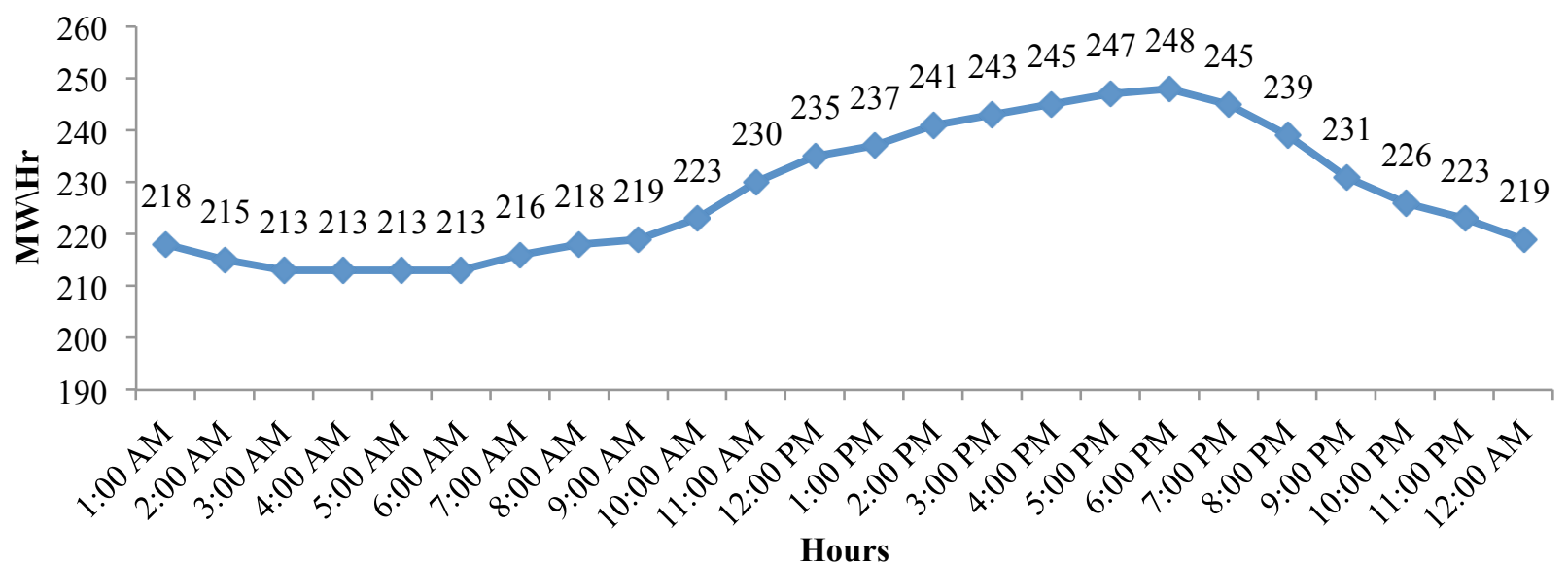

Figure 4.10: Graphical representation of electricity requirement in Malls 
Toronto Malls are consuming approximately $212 \mathrm{MW} / \mathrm{Hr}$. Most of the malls are operating in general timings which are 9:00 am till 9:00 pm but there are some malls which are operating from 10:00 am to 10:00 pm. Generally, the power consumption during the day time is relatively high as well as evening time. There is a technique which is known as "daylight saving" that is widely practiced in Canada. The rooftops of the malls are constructed in such a way that in the afternoon there is enough light because of the sun and making the malls bright and fully lighted in the daytime. Power consumption is relatively low at night because the mall does not operate in nighttime. As soon as the suns comes out, people start to arrive to open their shops in malls in order to start the day. The power consumption starts to grow around 8:00 am. In early morning malls are not busy, whereas in the daytime consumption rate starts to grow. We can see in the graph that the consumption is higher because of the customers coming in and evening rush hours. Mostly at evening times, people return from their work and they usually visit the malls thus making power consumption high. The power consumption gradually starts to decline around 10:00 pm, as you can see in above graph and it stays almost same until next day. This generally happens in all the malls of Toronto.

\subsection{Industrial Assessment}

Around 5,100 manufacturing industries are present in Toronto that have almost 120,000 people employed. As compared to other sectors, manufacturing jobs are mostly full time jobs, and they offer permanent positions to their employees. The major manufacturing industries in Toronto include: Fashion and Apparel, Food and Beverage, Aerospace, Paper-making, Packaging and Printing, Plastics and Chemicals, Metals and machinery, Pharmaceutical and life sciences, Computer and electronics.

Manufacturing industries are a source of strength for Toronto's traditional diversification here. Around $40 \%$ of immigrants are engaged in manufacturing industries in Toronto. Canada exports around $65 \%$ of its manufactured products. Toronto city's property taxes are approximately around $\$ 240$-Million which are paid by the Manufacturers. These taxes include education taxes and some other levies [24]. 


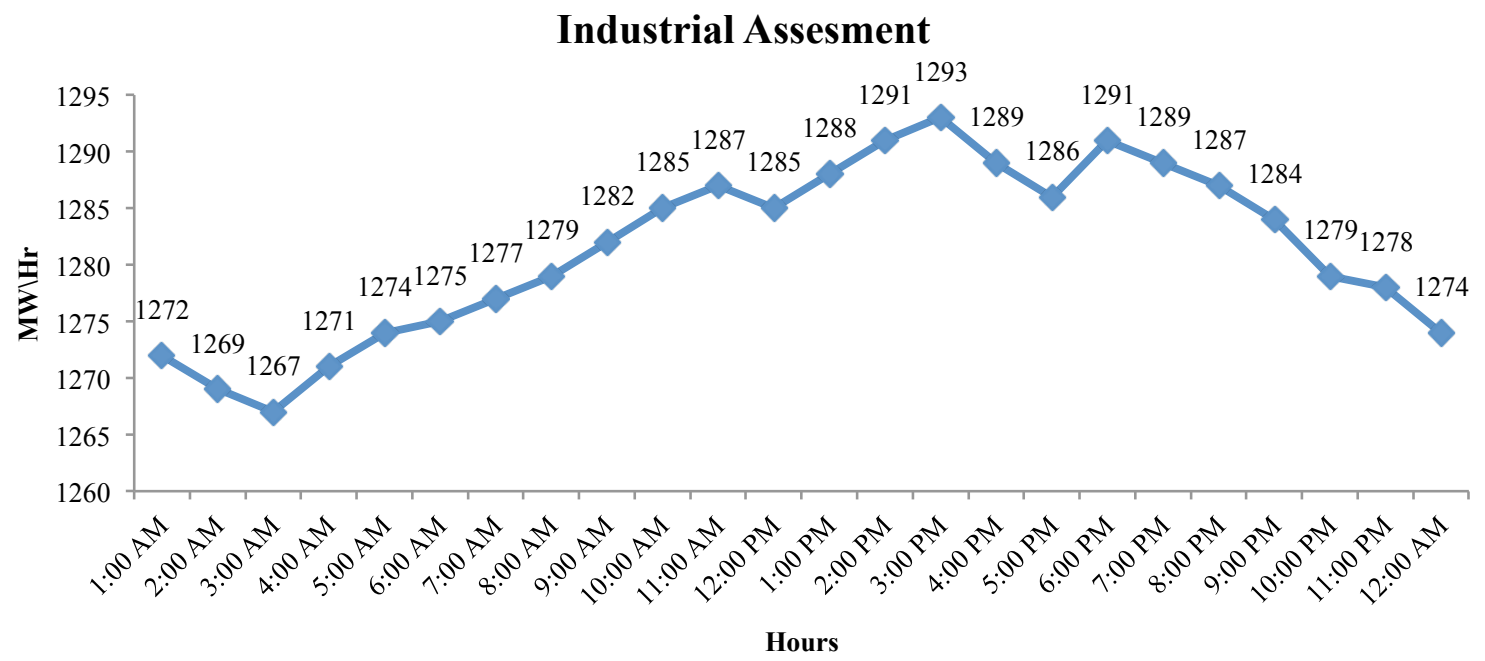

Figure 4.11: Graphical representation of electricity requirement in Industries

This graph shows the trend of energy consumptions in the city of Toronto. The consumptions vary greatly from hour to hour the entire day. On average, the industries in the city of Toronto require around $1283 \mathrm{MW} / \mathrm{H}$. From the graph we can indicate that after $3.00 \mathrm{am}$ in the morning the energy consumption starts increasing gradually as the day starts, around 3:00 pm we can see that the electricity consumption is at its peak because of the usage of high technical instruments and working projects. On the other hand the consumption rate starts decreasing because of the end of the day and it is minimum at 3:00 am in the morning. Some Industries in Toronto never shut down but usually the production decreases at mid night, which is due to cost, power consumption and not to many work forces available.

\subsection{Shops Assessment}

Toronto has seen a fast growth in shopping markets in North America. From very high luxury brands to average price brands, all are easily available. The verity is vast to cater every type of budget. The diversified culture makes the shops more unique. Toronto have very famous neighborhood and in those neighbor there are famous shops having huge variety. 
Popular city of Toronto in terms of street shops are Queen West, Chinatown, Leslie Ville, Greek town on Danforth and famous off all Downtown. In our assessment, we like to focus on power consumption in shops. As we know Toronto is a big city, it is a very challenging task to get the exact number of shops, which are presented in city of Toronto. In our study we were able to determine that in downtown Toronto there are approximate 900 shops are present. In which every type of shop is present from convenience store to a coffee shop. The major food markets of Canada like Loblaw's and Sobeys follow the timings like between 8:00 am to 10:00 pm or 9:00 am to 9:00 pm.

\section{Shops Assessment}

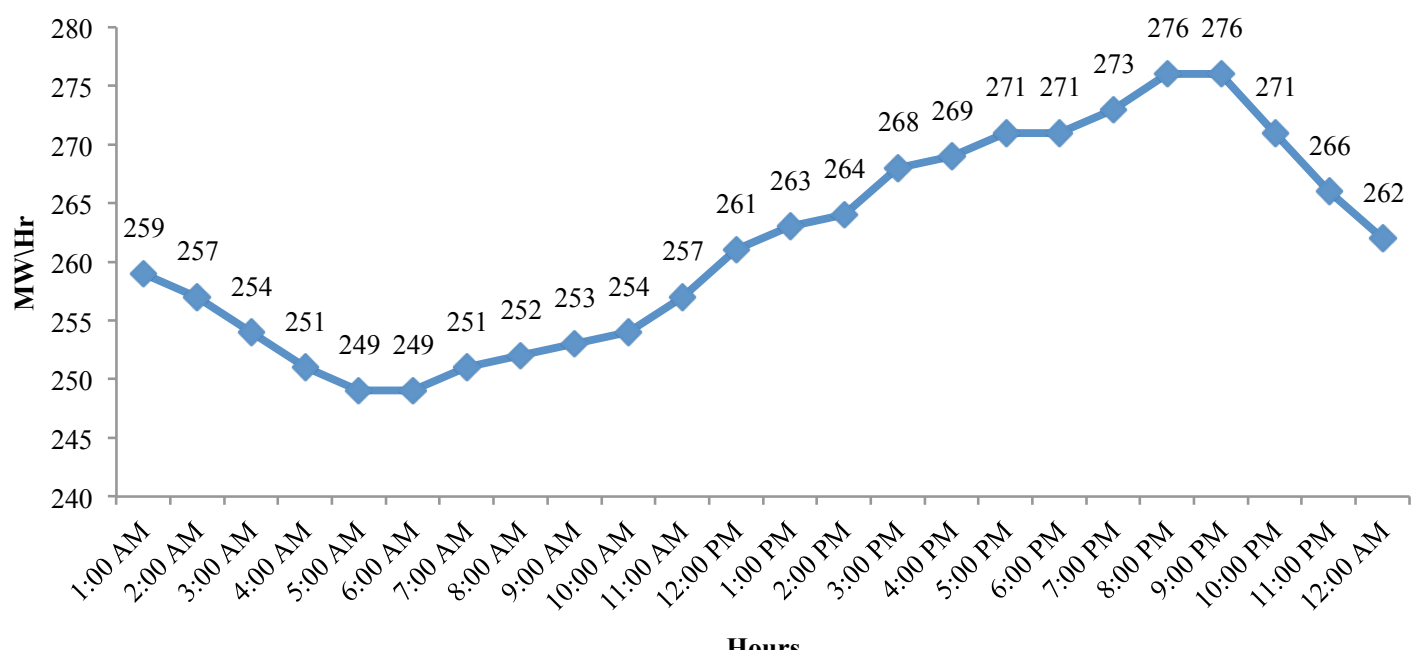

Figure 4.12: Graphical representation of electricity requirement in Shops

Most of the shops operate in daytime hours from 8:00 am to 10:00 pm. In the above graph we can see the rise in power consumption is getting higher due to high demand of electricity as more people are outside and would like to fulfill their requirements. The consumption rate is higher usually around 8:00 pm-10:00 pm. After 10:00 pm, the demand usually goes down and it declines. Usually there are only few shops operating thus making the demand low at night. The power consumption is not very high in those areas. Generally, City of Toronto shops require $246 \mathrm{MW} / \mathrm{Hr}$ to consume but the demand varies. 


\subsection{Miscellaneous Assessment}

This is a diverse assessment. In this category we are shifting our focus to tourist and fun places in Toronto. Toronto has a good number of destinations and they are usually busy throughout the year. This category includes $\mathrm{CN}$ tower, Rogers Center, Air Canada Center, Ripley's Aquarium, Toronto Zoo and the famous Harbour-front Center. Nightlife in Toronto is one of the best in the region and it is also very famous amongst tourists. There are also some sports centers that are open late in night hours.

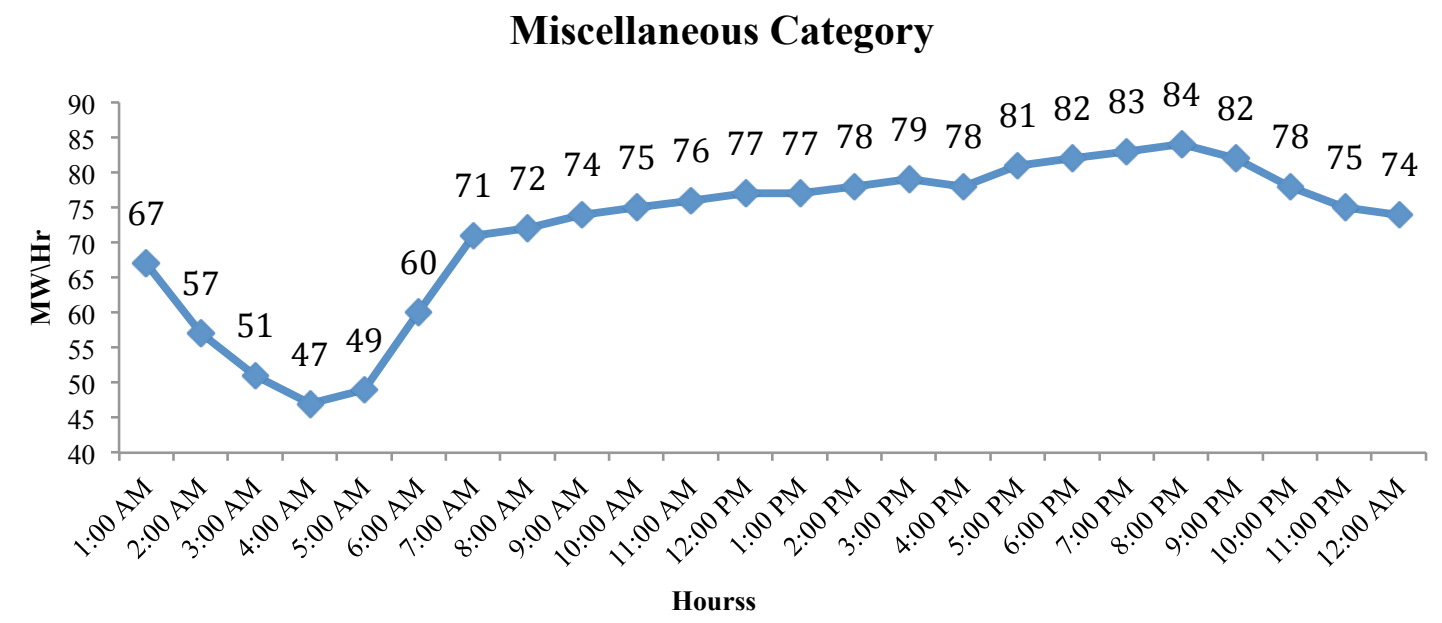

Figure 4.13: Graphical representation of electricity requirement in Miscellaneous

Power consumption in this category is consistent throughout the whole year. For example the Rogers Center and Air Canada Center re the major sporting venues for events but they are not limited to sports events; sometime they host big concerts and other entertainment venues. Generally, power consumption is relatively high in evening time. The power goes down from midnight to 4:00 am. Most of the bars are open until 2:00 am. After that power consumption is relatively low until next day. The City of Toronto has approximate 90 major attractions and the power consumption is approximately $67 \mathrm{MW} / \mathrm{Hr}$. 


\subsection{Combined Categorical Assessment}

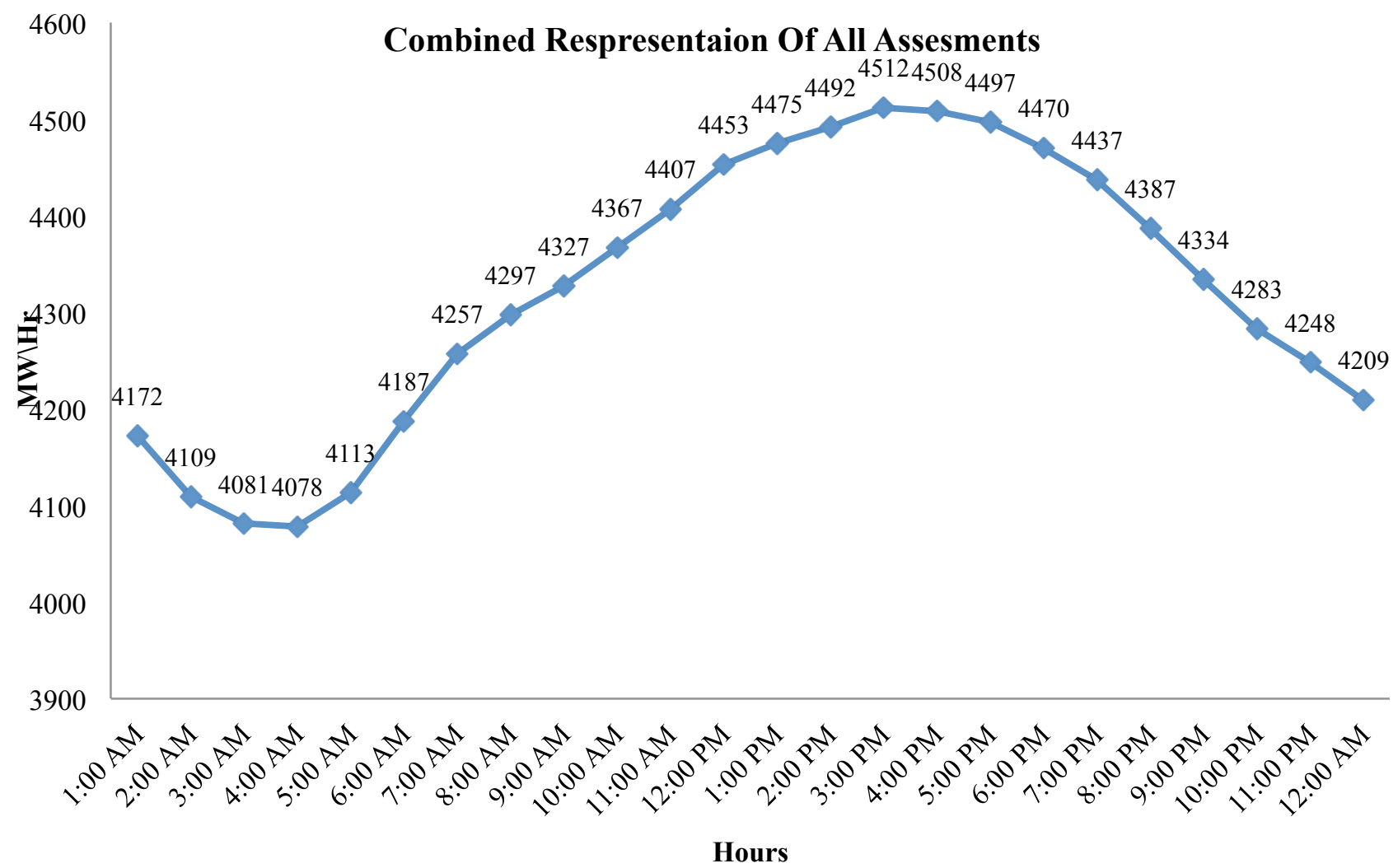

Figure 4.14: Graphical representation of all the categories

In this graph, we have merged all the categories and generated a single graphical representation. Through which we can easily understand that our City of Toronto approximately consuming $4237 \mathrm{Mw} / \mathrm{Hr}$. By looking at the graph, it's easy to understand that power consumption rate is higher during the daytime as compared to evening and nighttime. During the day, our demand rises from 10:00 am. This is generally happening due to involvement of various factors. By the evening time, we can see the power consumption is starts to decline and this reduction in power consumption is continuing through out the evening and night. Through this frequency of changing in power consumption demand we can easily understand that power consumption varies hour by hour but generally it's higher in daytime. 


\subsection{Emerging Technologies in Ontario}

\subsubsection{Smart Grid:}

"Smart Grid" is defined as the transformation of the existing electrical network that consist of bi-directional course of information and electricity in order to attain the subsequent targets: deliver customers with additional selections on how, when, and how much electricity they use; self-heal in case of disorders, physical and cyber-attacks, and natural disasters; tie with a widespread display of energy foundations, Except this to generate energy by power plants, like renewable energy producers; it also deliver improved power quality, and more effectual distribution of electricity [25].

The Smart Grid has following advantages

- Intelligent - having the capability of sensing system excesses and redirecting power to avoid or lessen a potential outage; of working separately when circumstances demand resolve earlier than individuals can reply and obligingly in supporting the goals of services, consumers and regulators [25].

- Efficient - It is accomplished by meeting an increased consumer demand without the accumulation of groundwork [25].

- $\quad$ Accommodating - It has the capability of producing power via energy from almost any fuel source containing solar and wind as easily and transparently as coal and natural gas [25].

- Motivating - empowering real-time declaration among the customer and service so clients can modify their energy consumption established on single preferences, such as worth and/or ecological anxieties [25].

- $\quad$ Opportunistic - generating novel chances and arcades related to capability to capitalize on plug-and-play revolution anywhere and when suitable [25] . 
- $\quad$ Resilient - progressively unaffected to violence and natural cataclysms because they are more decentralized and secure with Smart Grid security protocols [25].

- "Green" - They are more eco-friends and offer honest path near important ecological development [25].

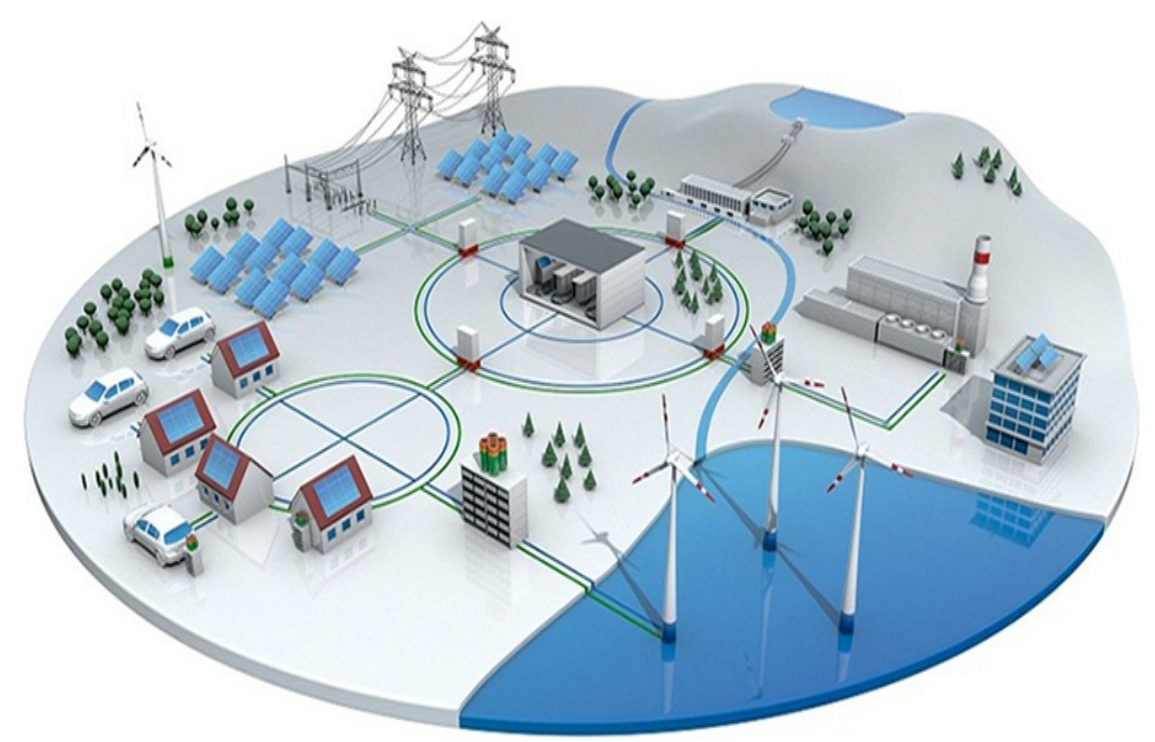

Figure 4.15: A Smart Grid [26]

\subsubsection{Smart Meter}

Ontario has complete an imposing twitch to authorizing customers via its judgment to order that all services prepare their inhabited and minor corporate clients with a smart meter by 2010. This initiation of two-way message path among consumers and utilities, will lead to develop future smart grid advancement [2]. 


\subsubsection{Smart Metering \& Energy Monitoring}

The Ontario government made an announcement that all regular electricity meters will be replaced by "smart meters" in the future [2]. A "smart meter" is an innovative electrical meter that accounts energy use per hour basis. These meters are essential for record of daytime billing because as it offers interval data, which permits efficacies to charge for electricity at diverse rates through the day [2].

Various families in apartments pay their energy charges as a part of monthly rent therefore are unaware of their total energy usage with no financial responsibility. It is well established that transferring the charge of energy to the purchaser will upshot in instant energy reserves. The thorough info taken by the Smart Meter can develop an invaluable tool to assess energy depletion beatings and can support the user in handling their electricity prices. Though, the existing initiative is attentive on economic billing and not the user checking of the energy they use [2].

Constructing energy checking is at a very elementary level in Ontario. A classic car has additional act watching than a representative house; nevertheless it charges a segment as abundant. Owners have slight thoughtful of the energy currents in their homes and have partial implements to provide them comprehensive info [2].

The energy bills contain evidence of electricity used in past not presently exactly like that of car driver who knows always that how much gas was used yesterday? Innovative energy displays intensify the user energy attentiveness via providing real-time energy practices in $\mathrm{kW}$, $\mathrm{kWh}$ and dollars per hour. In adding several can display the GHG releases in $\mathrm{kg} /$ hour. Advanced monitors performance like an "electricity speedometer" in the home-based, building consciousness of power rate on a real-time basis [2].

Europe and Japan are already using these building energy monitors and now Canada is taking the initiative to use monitors. Several metropolises like Ottawa are associating with dealers to model the use of advanced energy monitors in their dominion [2]. 


\subsection{Ontario's Green Button Initiative}

In November 2012, a partnership was created between MaRS Discovery and the District to initiate the Green Button facility in Ontario. The inventiveness is established on the Green Button activity is done by the United States Department of Energy in 2011 [27].

Driven by the Ministry of Energy and MaRS Discovery District, a working assembly was made with the Evidence and Privacy Commissioner of Ontario and assemblies from the vitality subdivision to acknowledge and implement the "Green Button information standard" - a shared setup for customers to unequivocally contact their information from their electric utilities [27].

The preparatory phase of the Green Button Initiative is called "Download My Data" and licenses customers to download their power use information from their electric utility's site by tapping on a green button [27]. Approx. $60 \%$ of the electricity's customers, who have access to Download My Data [27].

Some of the utilities have been taking an initiative to give an access to download my Data

on the Internet. Following utilities are: Hydro One, London Hydro, Hydro Ottawa, Toronto Hydro, North Bay Hydro, Peterborough Utilities, Guelph Hydro Power stream and Festival Hydro. Additional administrations are instantly operational close start Download My Data in the advancing months, including Kingston Hydro, Milton Hydro, Veridian Connections and Erie Thames Powerlines [27]. 


\section{Conclusion}

Nowadays Renewable energy sources are considered as one of the important technologies. It helps to develop a green environment, reduce emissions and create a healthy impact for the citizens. In our report, we have focused on renewable energy sources, through which we generate electricity in the city of Toronto. We would like to mention a few key findings and recommendations for future work, which can be conducted.

In our study we concluded that by using only renewable energy sources such as Solar, Hydro and Nuclear, the City of Toronto could generate enough electricity to fulfill the need of the entire city. It also came to our observance that in Ontario which usually depends on nuclear technology, because it is the main source, which generates high amount of electricity in the province, whereas from nuclear power we will be able to generate enough electricity, which will last long. It also has a disadvantage in terms of high maintenance cost-such as shutting down the nuclear plant for maintenance purposes, by doing that we rely on other sources of energy generations and one of the main disadvantage is to dispose nuclear waste. So, by shifting our focus to only renewable sources, we will be able to reduce the cost of maintenance and also produce clean energy, which is beneficial to the environment. Through this study we found out that if we install more renewable sources in Toronto or surroundings areas, we will be able to minimize the cost of electricity, which is beneficial for the consumer, and reduce the cost to maintain nuclear plants. It will help the municipal government and also the stakeholders.

Moreover in future, research can be conducted on energy storage technologies. Ontario generates enough electricity but the province does not have a proper energy storage system, so in order to save the electricity rather than giving the electricity to other province in negative prices, we should improve our energy storage systems.

In our report, we have discussed summer and winter consumption requirements in townhouses and residential building categories. We have noticed by focusing only on peak time hour, we can work on the peak-saving system to cut down the cost and the load on the power generation station so we can avoid power outages. Also we have noticed that the consumption 
rate of electricity is higher in other categories during office hours. We can further explain this report by focusing on the cost of electricity. We follow three different TOU (time-of-use) in the electricity bill. We can create such techniques which focuses on seasonal i.e. summer and winter peak demand of electricity. Furthermore in our study report we have seen the graphical representation of electricity in different TOU, which usually happens during the weekdays. Usually on weekend and saturated holidays have seen the off-peak demand load in entire day.

One of the main areas of focus of this project is to use renewable sources in city of Toronto, as we have distributed the data into several categories, we can also work on each category and see how they perform while we are using renewable sources, while working on each category by breaking down that particular category of its exact available unit values in cities e.g. (residential building, which are approx. 750 buildings). After breaking it down we will be able to find out how much electricity is required in that particular building and would conduct a survey on it to see if we are able to provide that particular load requirement by using renewable sources such as wind and solar.

We recommend that Toronto should move towards Smart Grid technology, as it is an emerging technology, which can lead Ontario towards success. Emission expenses or caps on aggregate pollution, with tradable emission grants, are illustrations of approaches to internalize the expenses of pollution, making a more leveled space for renewable energy sources. To ensure there will be a lot of energy later on, it is dependent upon every one of us to utilize energy wisely. The City of Toronto's planners should work on initiating energy saving plans, or providing awareness programs to the citizens of Toronto and making our youth to realize the importance of saving electricity in their lives. Concerns about the greenhouse impact and an unnatural weather change, air contamination, and energy security have prompted expanding investment and more improvement in renewable energy sources, for example, solar, wind, geothermal, wave power and hydrogen. However we will have to keep on using fossil energies and nuclear energy until new innovations can supplant them. The future is our own, however we require renewable energy sources to get there. 


\section{References}

1. Distributed Generation and The Future of Ontario's Electricity Grid. (n.d.). Retrieved September 9, 2015, from http://www.thinkingpower.ca/events_distgen.cfm

2. Energy Efficiency and Beyond on Toronto's Sustainable Energy Plan. (2007). Toronto. Retrieved from http://www.toronto.ca/legdocs/mmis/2007/pe/bgrd/backgroundfile4989.pdf

3. Toronto Facts - Your City - Living In Toronto, City of Toronto. (n.d.). Retrieved June 15,2015 , from

http://www1.toronto.ca/wps/portal/contentonly?vgnextoid=57a12cc817453410 VgnVCM 10000071d60f89RCRD

4. Census subdivision of Toronto, C - Ontario. (n.d.). Retrieved June 15, 2015, from https://www12.statcan.gc.ca/census-recensement/2011/as-sa/fogs-spg/Facts-csdeng.cfm?Lang=eng\&GK $=\mathrm{CSD} \& \mathrm{GC}=3520005$

5. Supply Overview. (n.d.). Retrieved August 9, 2015, from http://www.ieso.ca/Pages/Power-Data/Supply.aspx

6.Ontario's Electricity System. (n.d.). Retrieved June 15, 2015, from http://www.energy.gov.on.ca/en/ontarios-electricity-system/

7. About Renewable Energy. Natural Resource Canada. (n.d.). Retrieved November 23, 2014, from http://www.nrcan.gc.ca/energy/renewable-electricity/7295\#wind

8. Electricity - Ontario's Supply is a Diverse Mix of Sources. (2013, February 14). Retrieved September 9, 2015, from http://blog.powerstream.ca/2013/02/ontarioselectricity-supply-diverse-mix-sources/

9. Ontario's Long-Term Energy Plan. (n.d.). Retrieved September 9, 2015, from http://www.energy.gov.on.ca/en/ltep/

10. Top 10 Renewable Energy Sources - Listverse. (n.d.). Retrieved November 23, 2014, from http://listverse.com/2009/05/01/top-10-renewable-energy-sources/

11. Renewable energy policies and barriers," Fred Beck and Eric Martinot, in Encyclopedia of Energy, ed. Cutler Cleveland (Academic Press/Elsevier Science, San Diego, 2004), pp. 365-383. Surveys a broad array of renewable energy policies from around the world and describes the key barriers which justify policy intervention. Copyright 2004 Academic Press/Elsevier Science

12. Electricity Prices. (2015, April 29). Retrieved June 17, 2015, from http://www.ontarioenergyboard.ca/OEB/Consumers/Electricity/Electricity Prices 
13. Leslie, K. (2014, January 20). Ontario paid $\$ 1$ billion to export surplus power in 2013, NDP say. Retrieved August 10, 2015, fromhttp://kitchener.ctvnews.ca/ontariopaid-1-billion-to-export-surplus-power-in-2013-ndp-say-1.1647299

14. Exhibit F Transformation \& Distribution Options Northern York Region. (2005). Ontario Power Authority Toronto, Ontario, 22-22.

http://www.ontarioenergyboard.ca/documents/cases/EB-2005-0315/exhibit_f_300905.pdf

15. U.S. Department of Energy (2007, June), "The potential benefits of distributed generation and rate-related issues that may impede its expansion," [Online]. Available: https://www.ferc.gov/legal/fed-sta/exp-study.pdf

16. International Energy Agency (2002). Distributed Generation in Liberalized Markets. Accessed at http://www.iea.org/textbase/nppdf/free/2000/distributed2002.pdf

17. U.S Climate Change Technology Program (2003). Technology options for the near and long term. Accessed at http://climatetechnology.gov/library/2003/tech-options/techoptions-1-3-2.pdf

18. Ontario Clean Air Alliance (2009). Opening the Door to Clean Power in Toronto: Removing barriers to combined heat and power and distributed generation. Accessed at http://www.cleanairalliance.org/files/ active/0/cesop-web.pdf.

19. Higginson, J., Ebrary CEL - York University., \& World Wildlife Fund (Canada). (2009). Distributed generation in Toronto: A stakeholder survey of barriers and benefits. [Toronto, Ont.]: Manifesto Sustainability Communications.

20. Andreolas, M. (2004, February 21). Mega Load Management System Pays Dividends. Retrieved June 17, 2015, from http://tdworld.com/distribution-managementsystems/mega-load-management-system-pays-dividends

21. Office of Electricity Delivery and Energy Reliability. (2015). Retrieved June 17, 2015, from http://energy.gov/oe/office-electricity-delivery-and-energy-reliability

22. Quick Facts. (2014). Retrieved 2015, from

http://www.tdsb.on.ca/AboutUs/QuickFacts.aspx

23. Cottrill, J. (2013, January 17). The Five Best Malls in Toronto. Retrieved June 17, 2015, from http://www.toronto.com/articles/the-five-best-malls-in-toronto/

24. What is the Toronto Industry Network? Retrieved 2015, from http://torontoindustrynetwork.com/

25.The smart grid: An introduction. (p. 17). (2008). Washington, D.C.: U.S. Dept. of Energy. 
26. Smart Grid. (n.d.). Retrieved September 11, 2015, from http://solutions.3m.com/wps/portal/3M/en_EU/SmartGrid/EU-Smart-Grid/

27. Ontario's Green Button Initiative. (2014, February 24). Retrieved September 18, 2015, from http://news.ontario.ca/mei/en/2014/02/ontarios-green-button-initiative-1.html 